\title{
The Non-hydrostatic Icosahedral Atmospheric Model: description and development
}

\author{
Masaki Satoh ${ }^{1,2^{*}}$, Hirofumi Tomita ${ }^{3,2}$, Hisashi Yashiro ${ }^{3}$, Hiroaki Miura ${ }^{4,2,3}$, Chihiro Kodama ${ }^{2}$, Tatsuya Seiki ${ }^{2}$, \\ Akira T Noda ${ }^{2}$, Yohei Yamada ${ }^{2,1}$, Daisuke Goto ${ }^{5}$, Masahiro Sawada ${ }^{1}$, Takemasa Miyoshi ${ }^{3}$, Yosuke Niwa ${ }^{6}$, \\ Masayuki Hara', Tomoki Ohno', Shin-ichi Iga ${ }^{3}$, Takashi Arakawa ${ }^{7,2}$, Takahiro Inoue ${ }^{7,2}$ and Hiroyasu Kubokawa ${ }^{1}$
}

\begin{abstract}
This article reviews the development of a global non-hydrostatic model, focusing on the pioneering research of the Non-hydrostatic Icosahedral Atmospheric Model (NICAM). Very high resolution global atmospheric circulation simulations with horizontal mesh spacing of approximately $\mathrm{O}(\mathrm{km})$ were conducted using recently developed supercomputers. These types of simulations were conducted with a specifically designed atmospheric global model based on a quasi-uniform grid mesh structure and a non-hydrostatic equation system. This review describes the development of each dynamical and physical component of NICAM, the assimilation strategy and its related models, and provides a scientific overview of NICAM studies conducted to date.
\end{abstract}

Keywords: Global non-hydrostatic model; Icosahedral grid; Global cloud-resolving simulations

\section{Review} Introduction

Diabatic heating due to the release of latent heat in deep convection is the primary heat source in the atmosphere, and it is interacted with the atmospheric general circulation, especially the tropical large-scale overturning circulations such as the Hadley and Walker circulations. Individual deep convective cells are associated with meso-scale circulations that have a horizontal scale of $\mathrm{O}(10 \mathrm{~km})$, and an upward convective core, along with a horizontal scale of $\mathrm{O}(\mathrm{km})$. Until recently, since the horizontal resolution of the global climate models that have been used for future climate change projections has been $\mathrm{O}(100 \mathrm{~km})$, such models require the use of cumulus parameterizations in order to incorporate the effects of deep convection instead of by explicitly resolving deep convective circulations. However, it is known that cumulus parameterizations significantly affect the results of climate model simulations and that they are the most ambiguous factor used in climate models (Randall et al. 2003).

\footnotetext{
* Correspondence: satoh@aori.u-tokyo.ac.jp

${ }^{1}$ Atmosphere and Ocean Research Institute, The University of Tokyo, 5-1-5 Kashiwanoha, Kashiwa, Chiba 277-85648, Japan

2Japan Agency for Marine-Earth Science and Technology, 3173-15, Showa-machi, Kanazawa-ku, Yokohama, Kanagawa 236-0001, Japan Full list of author information is available at the end of the article
}

To overcome the above-mentioned cumulus parameterization issue, global non-hydrostatic models that utilize a horizontal mesh interval of $\mathrm{O}(\mathrm{km})$ for global atmospheric circulation simulations have been developed. Such models explicitly calculate deep convective circulations over the global domain without using cumulus parameterizations. At the grid-resolvable scale, water vapor is saturated into the liquid or ice phase of water in the upward flow field in order to form clouds and is eventually converted to rain and snow through cloud microphysics processes. In global non-hydrostatic models, clouds are spontaneously organized and the multi-scale structures of convective systems are reproduced over the global domain.

The Non-hydrostatic Icosahedral Atmospheric Model (NICAM) (Tomita and Satoh 2004; Satoh et al. 2008; Satoh 2013) was first designed to be run with a horizontal mesh size approximately $3.5 \mathrm{~km}$ over the global domain by using the Earth Simulator (http://www.jamstec.go.jp/ es/en/) which was launched by the Japan Agency for Marine-Earth Science and Technology (JAMSTEC) in 2002. NICAM uses an icosahedral grid, as shown in Figure 1. Higher resolution grids are recursively subdivided from a coarser resolution grid. Hereinafter, we will refer to the grid division level as the g-level. The number of points, arcs, and triangles of the icosahedral grids with g-level $l$ are given as follows: 

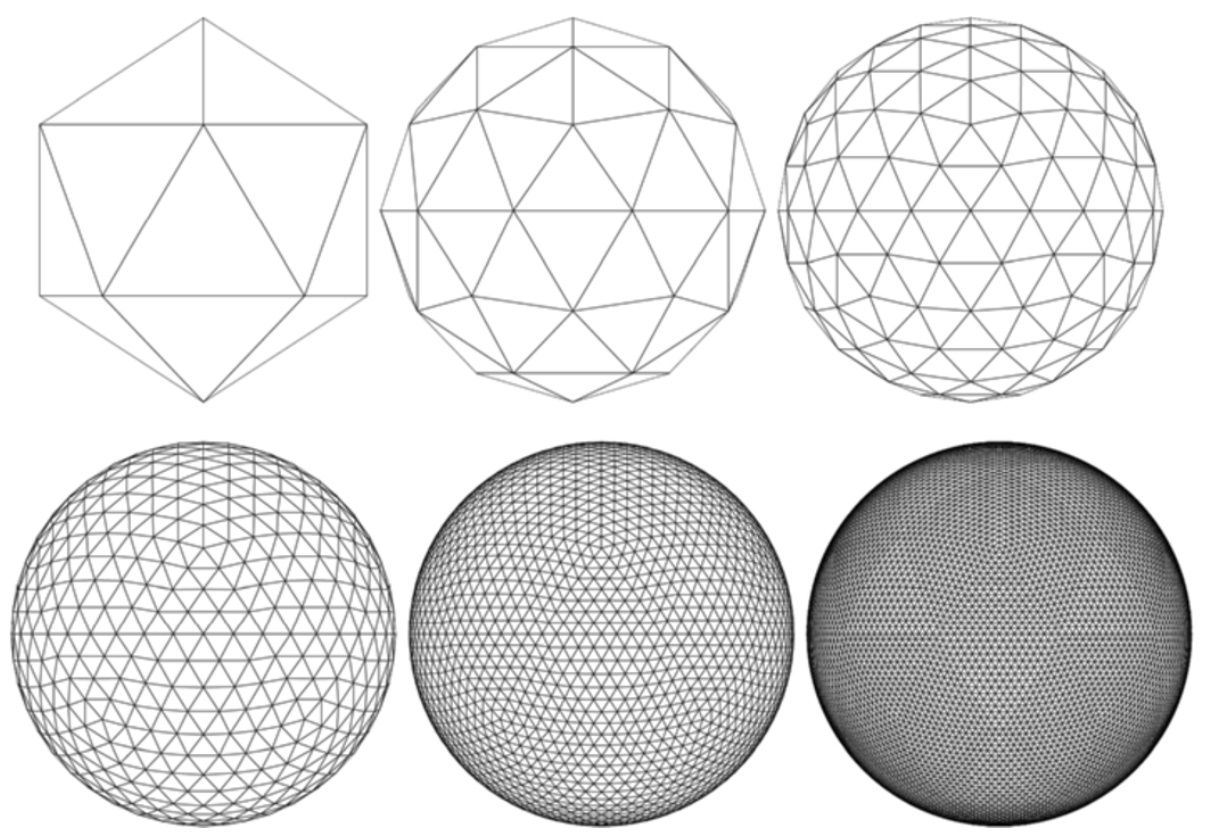

Figure 1 Icosahedral grids. Icosahedral grids for grid division levels of 0, 1, and 2 (top, from left to right), and 3, 4, and 5 (bottom, from left to right).

$$
\begin{aligned}
& N_{P}=10 n^{2}+2=10 \times 2^{2 l}+2, \\
& N_{A}=30 n^{2}=30 \times 2^{2 l}, \\
& N_{T}=20 n^{2}=20 \times 2^{2 l},
\end{aligned}
$$

where $n=2^{l}$. We define the average area of the triangles $\bar{A}$ and the average grid interval $\bar{\Delta}$ as follows:

$$
\begin{aligned}
& \bar{A}=\frac{4 \pi R^{2}}{N_{T}}=\frac{\pi R^{2}}{5 \times 2^{2 l}}, \\
& \bar{\Delta}=\sqrt{2 \bar{A}}=\sqrt{\frac{2 \pi}{5}} \frac{R}{2^{l}},
\end{aligned}
$$

where an Earth radius of $R=6,371.22 \mathrm{~km}$ is used. The values for each g-level are listed in Table 1.

NICAM has been shown to reproduce a realistic multi-scale cloud structure from a meso-scale to a planetary-scale cloud organization that is associated with the Madden-Julian Oscillation (MJO) (Madden and Julian 1971, 1972) at a g-level between $9(\bar{\Delta}=14 \mathrm{~km})$ and $11(\bar{\Delta}=3.5 \mathrm{~km})$ (Tomita et al. 2005; Miura et al. 2007b). By using the $\mathrm{K}$ computer, which is installed at the RIKEN Advanced Institute for Computational Science (AICS) in Kobe, Japan (http://www.nsc.riken. jp/index-eng.html), the resolution of NICAM has been recently increased to the subkilometer level, and it was shown that the deep convective core is more realistically resolved by using a g-level $13(\bar{\Delta}=870 \mathrm{~m})$ mesh simulation (Miyamoto et al. 2013; Figure 2). In the current study, various experiments including decadal continuous experiments and case sweep experiments (Miyakawa et al. 2014) were also conducted at g-levels between 9 and 11. Future projection studies such as those investigating changes in clouds and tropical cyclone activities are also investigated. The results are interpreted based on the more physically based cloud microphysics processes without the ambiguities of cumulus parameterizations.

This article describes the current development status, design, and concepts behind the individual components of NICAM. First, the background and an overview of studies related to the global non-hydrostatic model are reviewed. Then, the history of NICAM development and the scientific outcomes are summarized in the 'Scientific overview of NICAM' section, while the NICAM computational design is described in the 'Design, structure, development, and timeline' section. The two sections that follow describe the dynamical and physical components of NICAM, and their respective subsections describe each component of the physical processes. Next, the assimilation strategy is described. Finally, various NICAM usages that have been developed by modifying the original NICAM geometry are presented.

\section{Review of global non-hydrostatic models}

Thanks to the significant advances in high-performance computers over the last decade, global atmospheric simulations with a horizontal resolution of $\mathrm{O}(10 \mathrm{~km})$ can be achieved (Ohfuchi et al. 2004; Mizuta et al. 2005; Kinter et al. 2013; Wedi 2014). At enhanced horizontal resolution of less than $10 \mathrm{~km}$, traditional atmospheric 
Table 1 Number of points, arcs, triangles, and average grid interval of the icosahedral grids

\begin{tabular}{|c|c|c|c|c|c|}
\hline g-level & $\begin{array}{l}\text { Points } \\
N_{\mathrm{P}}\end{array}$ & $\begin{array}{l}\text { Arcs } \\
N_{\mathrm{A}}\end{array}$ & $\begin{array}{l}\text { Triangles } \\
N_{\mathrm{T}}\end{array}$ & $\begin{array}{l}\text { Average area } \\
\bar{A}\left(\mathbf{k m}^{2}\right)\end{array}$ & $\begin{array}{l}\text { Average interval } \\
\bar{\Delta}(\mathrm{km})\end{array}$ \\
\hline 0 & 12 & 32 & 20 & $5,100,996.991$ & $7,142.126$ \\
\hline 1 & 42 & 122 & 80 & $1,275,249.248$ & $3,571.063$ \\
\hline 2 & 162 & 482 & 320 & $318,812.312$ & $1,785.532$ \\
\hline 3 & 642 & 1,922 & 1,280 & $79,703.078$ & 892.766 \\
\hline 4 & 2,562 & 7,682 & 5,120 & $19,925.769$ & 446.383 \\
\hline 5 & 10,242 & 30,722 & 20,480 & $4,981.442$ & 223.191 \\
\hline 6 & 40,962 & 122,882 & 81,920 & $1,245.361$ & 111.596 \\
\hline 7 & 163,842 & 491,522 & 327,680 & 311.340 & 55.798 \\
\hline 8 & 655,362 & $1,966,082$ & $1,310,720$ & 77.835 & 27.899 \\
\hline 9 & $2,621,442$ & $7,864,322$ & $5,242,880$ & 19.459 & 13.949 \\
\hline 10 & $10,485,762$ & $31,457,282$ & $20,971,520$ & 4.865 & 6.975 \\
\hline 11 & $41,943,042$ & $125,829,122$ & $83,886,080$ & 1.216 & 3.487 \\
\hline 12 & $167,772,162$ & $503,316,482$ & $335,544,320$ & 0.304 & 1.744 \\
\hline 13 & $671,088,642$ & $2,013,265,922$ & $1,342,177,280$ & 0.076 & 0.872 \\
\hline 14 & $2,684,354,562$ & $8,053,063,682$ & $5,368,709,120$ & 0.019 & 0.436 \\
\hline
\end{tabular}

The g-level is the grid division level. Here, $R=6371.22 \mathrm{~km}$.

general circulation models (AGCMs) encounter fundamental difficulties in their dynamic framework formulation as well as in their computational efficiency. As their resolutions increase, AGCMs can capture flow features with comparable scales of motion in the horizontal and vertical directions (such as deep convection and fine-scale gravity waves) that can invalidate the hydrostatic approximation. Although deep convective systems in the tropics play key roles in global atmospheric circulations, they have not been directly resolved by AGCMs, and their effects have only been considered in a parameterized form
(Arakawa 2004). The effects of fine-scale gravity waves that are parameterized as gravity wave drag in AGCMs can be captured as the resolution increases, but the propagation of such gravity waves will be incorrectly calculated unless the non-hydrostatic effect is taken into consideration (Iwasaki et al. 1989).

Regarding the numerical algorithm, many of the existing AGCMs employ the spectral transform method to represent spherical fields, and it has been pointed out that spectral transforms become increasingly inefficient for high-performance computing as the horizontal resolution

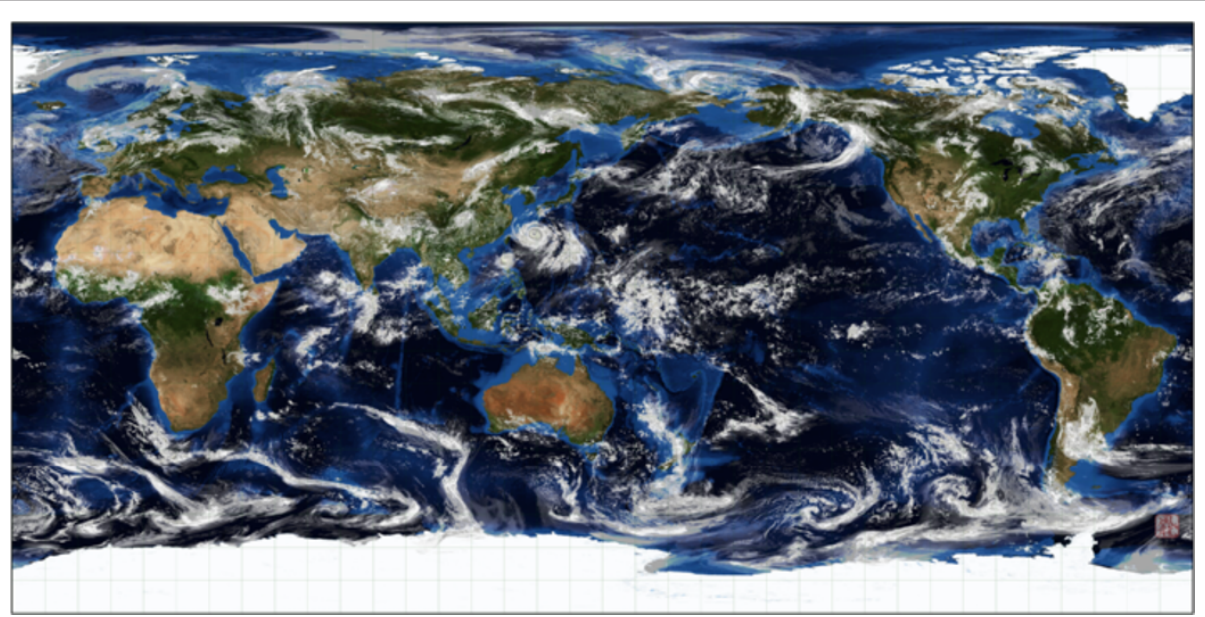

Figure 2 Cloud distribution simulated by the NICAM 870 m grid spacing experiment for 6:00 UTC 25 August 2012 (Miyamoto et al. 2013). 
increases (e.g., Stuhne and Peltier 1996; Taylor et al. 1997; Randall et al. 2000; Satoh et al. 2005; Cheong 2006; Tomita et al. 2008; Wedi 2014). Another problem that occurs during computation on a massively parallel computer is that the spectral transform method requires extensive data movement between computer nodes. Although the double Fourier transformation method has been proposed as an alternative (e.g., Cheong 2006), this method still requires global communication between computer nodes.

To increase the horizontal resolution beyond $\mathrm{O}$ $(10 \mathrm{~km})$ in a global atmospheric model, the governing equations and numerical algorithms must be reconsidered. More specifically, the governing equations must be non-hydrostatic, and the grid point method replaces the spectral method. As for the familiar latitude-longitude grid (lat-lon grid), however, the grid spacing near the poles becomes drastically reduced as the horizontal resolution is increased, which means that reduced grids are generally required to avoid severe time interval restrictions for the Courant-Friedrichs-Lewy (CFL) condition. In principle, the semi-Lagrangian, semi-implicit (SLSI) approach (cf. Laprise 2008; Staniforth and Wood 2008) could be employed to overcome the requirement of the CFL condition. Several authors (Semazzi et al. 1995; Cullen et al. 1997; Qian et al. 1998; Côté et al. 1998; Yeh et al. 2002; Davies et al. 2005; Wedi and Smolarkiewicz 2009; Wood et al. 2013) have used the lat-lon grid to solve a set of non-hydrostatic equations using the SLSI approach in order to acquire a larger time interval for integration. However, it is unclear how effective the elliptic solvers, which were developed for SLSI schemes, would be for ultra-high-resolution calculations, even though it has been recently proven that a multi-grid approach is an ideal solver for massively parallel computers (Heikes et al. 2013).

The pole problem can be overcome by using grid systems with quasi-homogeneous grids over the sphere. One such grid is the icosahedral grid, which is currently one of the major grid systems used for high-resolution global atmospheric modeling. Primitive (hydrostatic) equation global models using icosahedral grids have been developed at Colorado State University for climate modeling (CSU AGCM) (Ringler et al. 2000), Deutscher Wetterdienst for numerical prediction modeling (GME) (Majewski et al. 2002), the National Oceanic and Atmospheric Administration (NOAA) for the Flow-following finite-volume Icosahedral Model (FIM) (http://fim.noaa. gov/), and the Laboratoire de Météorologie Dynamique (DYNAMICO) (http://www.lmd.polytechnique.fr/ dubos/ DYNAMICO/). Global non-hydrostatic models using icosahedral grids are also being developed by several international groups including the geodesic grid model at Colorado State University (UZIM; http://www.cmmap.org/ research/models.html), the Icosahedral Non-hydrostatic model (ICON) at the Deutscher Wetterdienst and the Max
Planck Institute for Meteorology (http://www.mpimet.mpg. de/en/science/models/icon.html; Zängl et al, 2014), the Model for Prediction Across Scales (MPAS) at the National Center for Atmospheric Research (Skamarock et al. 2012), and the Non-hydrostatic Icosahedral Model (NIM) at NOAA (http://www.esrl.noaa.gov/gsd/ab/ ac/GPU_Parallelization_NIM.html). Entries for all these models can also be found at https://www.earthsystemcog. org/projects/dcmip-2012/. As for other types of grid models, cubic grids are also candidates for high-resolution atmospheric models (McGregor 1996; Lin 2004; Putman and Suarez 2011).

In Japan, the icosahedral atmospheric model has been created by using a non-hydrostatic system, i.e., NICAM (Tomita and Satoh 2004; Satoh et al. 2008; Satoh 2013; http://nicam.jp/). Development of NICAM began around 2000. Since high-resolution modeling has now entered the mainstream worldwide, NICAM has joined a number of international high-resolution numerical modeling projects, such as the Athena Project (Kinter et al. 2013) with the Integrated Forecast System (IFS) (Jung et al. 2012) and the Icosahedral-grid Models for Exascale Earth system simulations (ICOMEX) (Zängl et al. 2011) with ICON, MPAS, and DYNAMICO.

\section{Scientific overview of NICAM}

While more than a decade has passed since the development of NICAM began, the first milestone was reached in 2004 when Tomita and Satoh (2004) began finalizing the dynamical core of the model. Two unique characteristics of the NICAM dynamical core are the use of the spring dynamics to construct a modified icosahedral grid (Tomita et al. 2001, 2002) and the use of a flux form non-hydrostatic system which guarantees conservation of mass and energy (Satoh 2002, 2003). Tomita et al. (2001, 2002) constructed NICAM's icosahedral grids by improving the numerical accuracy of differential operators and using spring dynamics to improve the homogeneity of the grid system. An improved version of the spring dynamics method, which is more homogeneous and applicable even for higher resolution, is also now available (Iga and Tomita 2014). NICAM uses a fully compressible (elastic) non-hydrostatic system to obtain statistically equilibrium states by performing long-timescale simulations. For this purpose, we devised a non-hydrostatic numerical scheme that guarantees the conservation of mass and energy (Satoh 2002, 2003). Tomita and Satoh (2004) implemented this non-hydrostatic scheme in their global model using an icosahedral grid configuration, with which they developed a dynamical core for NICAM. Since the split-explicit time integration scheme (Klemp and Wilhemson 1978) is used for the horizontal propagation of fast waves and for the implicit treatment of the vertical propagation of fast waves, multi-dimensional elliptic solvers are not required. To 
extend the original non-hydrostatic scheme to the global domain, the set of equations provided in Satoh (2002, 2003) is reformulated for spherical geometry and modified in order to make the equations suitable for an icosahedral grid configuration. The finite volume method is used for numerical discretization, so that the total mass and energy over the domain are conserved. The resulting model is suitable for long-term climate simulations.

NICAM is used for 'cloud-resolving simulations' by explicitly resolving convective circulation. This is accomplished by drastically increasing the horizontal resolution using high-power computing systems, such as Earth Simulator and the $\mathrm{K}$ computer. After finalizing the development of the dynamical core (Tomita and Satoh 2004), the first $3.5 \mathrm{~km}$ mesh global NICAM simulation was performed on Earth Simulator by Tomita et al. (2005) using the aqua planet configuration (Neale and Hoskins 2001). The results of this simulation clearly show multi-scale convective systems propagating near the equator (Satoh et al. 2005), which is similar to the propagation of the observed cloud clusters and super cloud cluster structure (Hayashi and Sumi 1986; Nakazawa 1988; Takayabu et al. 1999).

Tomita et al. (2005) conducted aqua planet experiments at three horizontal resolutions, g-levels 9, 10, and $11(\bar{\Delta}=14,7,3.5 \mathrm{~km})$, using the same physical schemes without cumulus parameterization. In their results, the multi-scale convective structure along the equatorial zone and the diurnal cycle of convective precipitation were reproduced similarly in all simulations, although the propagation speed along the equator and the phase lag of the diurnal cycle depends on the resolution. This result motivated us to use a combination of different horizontal resolution experiments with the same physical schemes when studying convective properties simulated by NICAM.

The results of the NICAM aqua planet experiment were analyzed intensively by Nasuno et al. (2007, 2008), Nasuno (2008), and Nasuno and Satoh (2011a, b), which showed the roles of the equatorial convective systems embedded in the multi-scale structure. Mapes et al. (2008) also investigated the persistent structure in the tropics in terms of the predictability of disturbances. The diurnal cycle of tropical convective precipitation was clearly simulated with the dependency of the phase lag on the horizontal resolution (Tomita et al. 2005). The semi-diurnal cycle was also captured. This was further investigated by Yasunaga et al. (2013) by using the NICAM aqua planet experiment. The detailed structures of convective systems near the tropopause were analyzed by Kubokawa et al. (2010).

The aqua planet configuration is used to test cloud changes that are related to increased surface temperatures in order to imitate global warming conditions. Miura et al. (2005) compared the cloud cover responses between NICAM and the Model for Interdisciplinary Research on Climate (MIROC) (Hasumi and Emori 2004), which is an ordinary resolution climate model (denoted as CCSR/NIES/ FRCGC in Miura et al. 2005), under the aqua planet condition. The comparison results show that the cloud cover simulated by NICAM increases in high-latitude regions, while that by MIROC decreases. Such a contrasting response to cloud cover is very interesting and should be analyzed in more detail, as will be described later in this section. The change in the meridional distribution of relative humidity is shown and compared to the other model results by Sherwood et al. (2010).

The aqua planet experiments of NICAM were compared to the other model results in Blackburn et al. (2013), and additional aqua planet experiments were conducted by Yoshizaki et al. (2012a, b) in order to investigate the multiple-scale convective structure along the equator.

A NICAM simulation that includes a realistic configuration with a land and sea contrast was performed by Miura et al. (2007a). The results of this simulation show not only realistically simulated tropical cyclogenesis but also a clear dependency of convective organization on a planetary boundary layer (PBL) scheme, specifically, water vapor transport. Using the simulated dataset, the diurnal variation of the convective systems over the Tibetan Plateau was analyzed by Sato et al. $(2007,2008)$.

A successful simulation of a realistic MJO event was presented by Miura et al. (2007b), in which a 1 month integration with a $7 \mathrm{~km}$ grid spacing and a 1 week integration with a $3.5 \mathrm{~km}$ grid spacing were performed. A large-scale cloud organization, its eastward propagation, and the multiple-scale structure of convective systems were realistically reproduced (Nasuno et al. 2009). The similarity of the simulation to the observed MJO was further analyzed by Liu et al. (2009). In addition, multiple tropical cyclones were realistically generated from the active cloud areas of the MJO. Particularly, Fudeyasu et al. (2008, 2010a, 2010b) analyzed the evolution of a tropical storm in detail, which was generated from the MJO 2 weeks after the initial condition.

Thanks to the high-resolution numerical simulations performed by Miura et al. (2007b), simulation results can be analyzed or used in various ways. The dataset consists of $7 \mathrm{~km}$ mesh and $14 \mathrm{~km}$ mesh grid data for 1 month from 15 December 2006 and $3.5 \mathrm{~km}$ mesh grid data for 1 week from 25 December 2006. The diurnal cycle of tropical convective systems was intensively analyzed by Sato et al. (2009). Convective momentum transports of the MJO were analyzed by Miyakawa et al. (2012). The dataset was compared with the satellite observations of the Tropical Rainfall Measuring Mission (TRMM) and CloudSat (Masunaga et al. 2008), the geostationary satellite, the Multi-functional Transport Satellite (MTSAT-1R) (Inoue et al. 2008), and CloudSat 
and Cloud-Aerosol Lidar and Infrared Pathfinder Satellite Observations (CALIPSO) (Inoue et al. 2010; Satoh et al. 2010; Ham et al. 2013), and with the estimation of cloud radiative forcing (Sohn et al. 2010). The dataset was also used to develop a cloud parameterization for coarser resolution AGCMs (Watanabe et al. 2009). The convective structure near the tropopause was also analyzed by Kubokawa et al. (2012). The energy spectrum and similar frequency spectra of the high-resolution data were analyzed by Terasaki et al. (2009) and Tsuchiya et al. (2011).

Following Tomita et al. (2005) and Miura et al. (2007b), studies of intra-seasonal variability (ISV) including MJOs and boreal summer intra-seasonal oscillations (BSISO) (Fu and Wang 2004) are unique areas of NICAM studies. Various aspects of the MJO and tropical disturbances simulated by Tomita et al. (2005) and Miura et al. (2007b) are being analyzed as mentioned above. NICAM studies are also collaborated with observational field campaigns of MJOs. Miura et al. (2009) examined an onset of MJO observed at the Mirai Indian Ocean cruise for the Study of the MJO-convection Onset (MISMO) field campaign (Yoneyama et al. 2008), suggesting a role of the sea surface temperature (SST) gradient in the western Indian ocean. Also, for the Cooperative Indian Ocean Experiment on Intraseasonal Variability in the Year 2011/Dynamics of the MJO (CINDY2011/DYNAMO) campaign (Yoneyama et al. 2013), Nasuno (2013) summarized a result from quasireal-time weather forecasting experiments that showed simulated characteristics of MJOs during the CINDY2011/ DYNAMO period in the boreal winter between 2011 and 2012. The quasi-real forecasting system using the stretch NICAM (Tomita 2008a; see 'Models related to NICAM' section) was developed particularly for use in collaboration with field experiments, as introduced by Oouchi et al. (2012). More statistical results for MJO simulations are shown by Miyakawa et al. (2014), who reported a good performance of MJO predictability by the hind cast approach with NICAM. BSISO simulations were analyzed by Oouchi et al. (2009a, 2014), Taniguchi et al. (2010), Yanase et al. (2010b), and Satoh et al. (2012a). In particular, they focused on relations between ISV and tropical cyclones, as described below, since ISV modulates large-scale vorticity distributions that generally lead to preferable conditions for cyclogenesis.

Tropical cyclones can also be adequately researched by using NICAM. Tropical cyclogensis and its evolution from the MJO were analyzed for boreal winter cases by Fudeyasu et al. (2008, 2010a, 2010b). For boreal summer, tropical cyclogenesis was found to be frequently related to ISV activities (Kikuchi and Wang 2010). The cyclone Nargis, which caused severe damage to Myanmar in May 2008, was successfully simulated and its relation to the northward propagation of BSISO in the Bay of Bengal was analyzed by Taniguchi et al. (2010) and Yanase et al. (2010a, 2012a). Oouchi et al. (2009a) simulated tropical cyclogenesis in the northwestern Pacific and showed its relation to the MJO. The effects of an equatorial Kelvin wave on an abrupt development of a tropical cyclone were clearly shown by Yanase et al. (2010b). Yanase et al. (2012b) also analyzed some statistical behaviors of tropical cyclones simulated by NICAM especially over the eastern Pacific. The impacts of a tropical cyclone on the Baiu rainfall were analyzed by Yamaura et al. (2013). The preferable conditions of tropical cyclogenesis were analyzed over the Atlantic domain (Satoh et al. 2013).

Tropical cyclone climatology and possible changes in the future projection of tropical cyclone activities are actively being researched using NICAM. For example, Satoh et al. (2012a) analyzed 8 years of boreal summer experiments that were conducted in the Athena Project (Kinter et al. 2013) in order to show the simulated climatology of tropical cyclones and produced results that show good relations between tropical cyclone activities and MJO activities. Future changes in the tropical cyclone structure were analyzed by Yamada et al. (2010, 2012), Yamada and Satoh (2013), and Emanuel et al. (2010).

NICAM simulations also contribute to the studies on Asian monsoon and tropical convective systems. For example, Oouchi et al. (2009b) provided a realistic distribution of precipitation during a boreal summer and showed its variation for diurnal and intra-seasonal timescales. Additionally, the resolution dependency of the diurnal cycle of convective systems was analyzed by Sato et al. (2009), and their results were found to be generally consistent with those of the aqua planet experiment (Tomita et al. 2005); as resolution becomes coarser, the timing of precipitation peak becomes increasingly delayed. Sato et al. (2009) also analyzed the diurnal evolution of tropical convective cold pools, while Fujita et al. (2011) analyzed the behavior of the diurnal convection over maritime continental regions. Dirmeyer et al. (2012) and Noda et al. (2012) also analyzed the diurnal cycle of precipitation over the global domain. A mechanism for the diurnal variation of summer precipitation over southern China was investigated by Satoh and Kitao (2013) using the stretched version of NICAM (see 'Models related to NICAM'section).

The use of a cloud microphysics scheme in NICAM experiments without cumulus parameterization leads to realistic behavior of cloud distribution in the horizontal and vertical directions. Furthermore, as seen in the paragraph below, it might even produce a different behavior of cloud feedback from that obtained by conventional climate models that use cumulus parameterization. Iga et al. (2007a) analyzed the climatological distribution of cloud cover and compared it with the data of the International Satellite Cloud Climatology Project (ISCCP) 
(Rossow and Schiffe 1999), while in a later study, Iga et al. (2011) analyzed upper tropospheric ice clouds and their sensitivity using various model parameters. Noda et al. (2010) investigated the importance of the subgrid turbulent process on cloud distributions. Kodama et al. (2012) showed the sensitivities of upper clouds to the choice of various cloud microphysics parameters. Satoh and Matsuda (2009) investigated how cloud microphysics affects upper clouds under an idealized radiative convective equilibrium condition.

As for the future simulations of cloud change by NICAM, Miura et al. (2005) showed the model's different behavior when compared to a coarse resolution AGCM (MIROC). In addition, Collins and Satoh (2009) showed that as a response that was different from the existing models, the upper cloud cover might increase, whereas the ice water path decreases under future warming conditions. Satoh et al. (2012b) analyzed their results and speculated that a future reduction in convective circulation could lead to a reduction in the ice water path under the warming condition. Tsushima et al. (2014) further investigated longwave cloud feedback and showed the possibility of a stronger positive feedback than other coarse resolution AGCMs. Yamada and Satoh (2013) analyzed the relation between cloud changes over the global domain and tropical cyclone changes. Kodama et al. (2014a) also analyzed the cloud changes associated with storm tracks simulated by the NICAM aqua planet experiments.

Recently, use of the $\mathrm{K}$ computer has allowed the horizontal resolution of NICAM to be increased. Miyamoto et al. (2013) performed (for the first time) a subkilometer mesh global domain simulation with grid spacing of $870 \mathrm{~m}$ (g-level 13) and 96 vertical layers (Figure 2). They showed that at a resolution of less than $1.7 \mathrm{~km}$, convective cores could be resolved by multiple grid cells. The ability to use the $\mathrm{K}$ computer introduces a new area of study for NICAM. Numerous MJO case studies are currently being conducted in order to evaluate their statistical predictability (Miyakawa et al. 2014). More than 10 years of continuous simulations have and are being conducted under present and future conditions in order to investigate future changes to tropical cyclones and other extreme events. The subsequent sections describe the improvements in the simulated climatology that have been made possible by improving the physical processes.

As described above, NICAM is usually run without using cumulus parameterization. In general, the horizontal scale of meso-scale phenomena ranges from a few to several hundred kilometers. It is not readily understood why a model with horizontal mesh spacing of $\mathrm{O}(10 \mathrm{~km})$ reproduces such meso-scale phenomena without subgrid convective parameterization. It is speculated that for relatively large-scale meso-scale convective systems, the statistical effects of circulation resolved by grids behave similarly to nature. Figure 3 shows resolution dependency of upper cloud distributions in the range of $\bar{\Delta}=28$, $14,7,3.5,1.7,0.87 \mathrm{~km}$ for the NICAM simulations conducted by Miyamoto et al. (2013). Although in that study, it was analyzed that the convective core becomes resolved at $\bar{\Delta}=1.7 \mathrm{~km}$. Figure 3 shows that the large-scale structure of upper clouds is nearly unchanged for these resolutions. This result implies that the usefulness of a model without cumulus parameterization depends on research targets of meteorological phenomena. Large-scale organized convective structures such as MJOs are, in general, well reproduced without using cumulus parameterization, even at the coarser horizontal resolutions around $\mathrm{O}$ $(10 \mathrm{~km})$ as also indicated by Holloway et al. (2013), while the precise simulation of details of meso-scale convective structure needs much finer resolutions (Bryan et al. 2003).

\section{Design, structure, development, and timeline}

A timeline of the development of NICAM is summarized in Table 2. As was previously mentioned, the development of NICAM started in 2000 at JAMSTEC. Through the construction of icosahedral grid systems (Tomita et al. 2001, 2002), a shallow water model (SWM) (Tomita et al. 2001, 2002) was initially tested. At the same time, new non-hydrostatic numerical schemes were being developed (Satoh 2002, 2003). By combining the two approaches, a three-dimensional (3D) dynamical core was eventually developed (Tomita and Satoh 2004). The resulting $3.5 \mathrm{~km}$ mesh high-resolution dynamical core experiments were examined by Iga et al. (2007b). Then, full-physics experiments have been underway since 2004. Furthermore, the dynamical schemes, computational stability, and a tracer advection scheme (Miura 2007; Niwa et al. 2011a) have improved. For physical processes, we have actively introduced more sophisticated schemes, especially for cloud microphysics (Grabowski 1998; Tomita 2008b; Seiki and Nakajima 2014) and PBL schemes (Nakanishi and Niino 2006, 2009; Noda et al. 2010). An accurate semiLagrangian scheme for sedimentation processes was developed for cloud microphysics schemes (Xiao et al. 2003). Aerosol processes (Suzuki et al. 2008) and atmospheric chemistry processes have also been introduced. Each component of the abovementioned physical schemes will be described in later sections of this review. Several NICAM-based systems are also currently under development, including atmosphere-ocean coupling and ensemble-based data assimilation systems, and downscaling methods for regional scale experiments have been developed for more advanced uses.

Since high-resolution simulations require large computational resources, the efficiency of state-of-the art supercomputers needs to be maximized. In general, weather/climate models use a large number of physical 


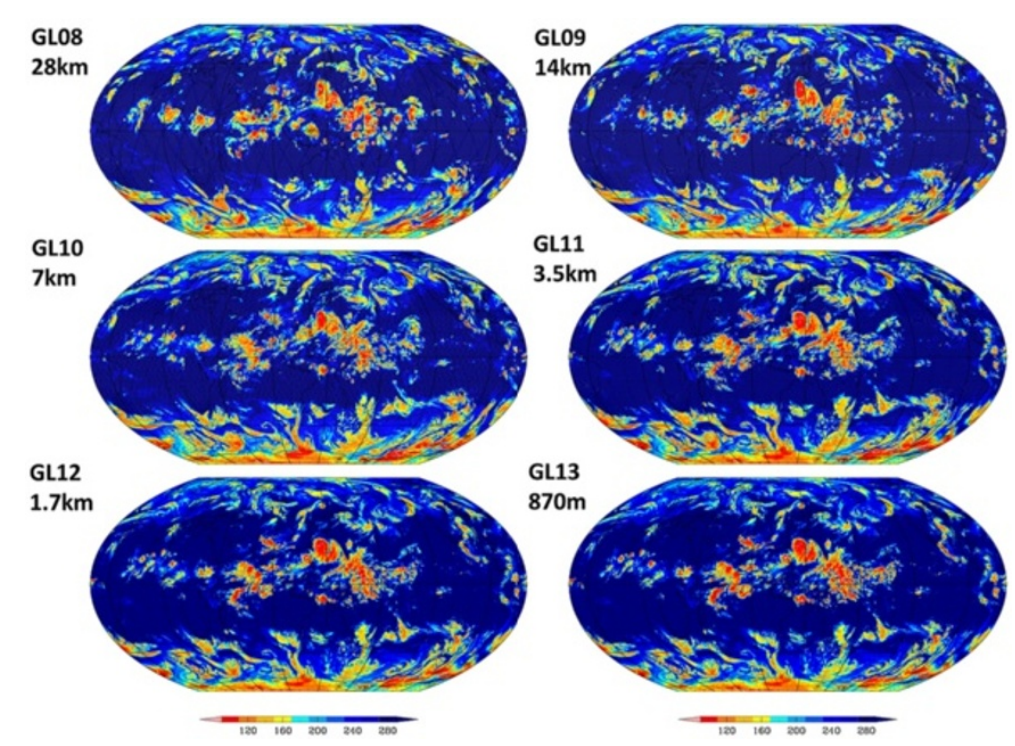

Figure 3 Resolution dependency of cloud structure simulated by NICAM between $\mathbf{2 8} \mathrm{km}$ and $\mathbf{8 7 0} \mathrm{m}$ grid spacing experiments. Cloud distributions simulated by NICAM between $28 \mathrm{~km}$ and $870 \mathrm{~m}$ grid spacing experiments for 6:00 UTC 25 August 2012, shown by the outgoing longwave radiation at the top of the atmosphere. The unit is $\mathrm{W} \mathrm{m}^{-2}$.

variables during computation, so the size of 3D arrays significantly increases with increases in spatial resolution. Large-sized, various, frequent data output is also needed for simulations. Taken together, these factors make it clear that weather/climate models require faster data throughput in all layers of a computer system. NICAM has been tactically designed to achieve efficient throughput at the 1) memory layer, 2) network layer, and 3) file input/output (I/O) layer.

Since numerous simple arithmetic operations are used for large arrays in NICAM algorithms, memory throughput is the most important aspect governing total computational efficiency. For example, when using Earth Simulator, the ratio of memory bandwidth to the floating-point performance (Byte/Flops ratio; hereinafter $\mathrm{B} / \mathrm{F}$ ratio) is 4 , which makes it easy to execute NICAM with a high degree of efficiency. However, in the past decade, the $\mathrm{B} / \mathrm{F}$ ratio has decreased during the recent evolution of supercomputers. As a result, when NICAM was implemented on the $\mathrm{K}$ computer at $\mathrm{B} / \mathrm{F}=0.5$, numerous optimizations had to be applied to improve the efficiency of computer performance. Saving memory transfers is one effective optimization tactic. To accomplish this, we suppressed the memory copies, reduced the intermediate arrays, and avoided unnecessary zero-filling. These changes had to be performed manually and required labor-intensive efforts. However, as a result of these optimizations, we succeeded in reducing the model execution time by $30 \%$.

To improve network throughput, the finite volume method with an explicit scheme was adopted to minimize the global communications, as described in the section 'Dynamics'. When 640 nodes on the K computer are used, the network communication of NICAM accounts for about $10 \%$ of the total elapsed time at the case of g-level $9(\bar{\Delta}=14 \mathrm{~km})$. This percentage increases as the number of nodes increases. Kodama et al. (2014b) developed an algorithm for optimally assigning of nodes in a network topology such as a torus/mesh.

For the file I/O throughput, NICAM adopts a distributed file I/O. If the output data are aggregated into a single file at the time of output, it would be easy to handle the file. However, NICAM cannot maximize the I/O throughput using such a single output file. The data of each region on the icosahedral grid of NICAM are output to a file at the node, and the icosahedral grid is converted into a lat-lon grid during the post-process. Generally, we use a simple bilinear interpolation for the post-process, although we have an option of another interpolation to keep conservation of area integration. A recently developed post-process program can run in parallel with the main model using a coupler (see 'Coupler' section). However, an increase in file size due to the higher resolution is a current issue, and we are planning to change the file type to a compressible standard format, such as Network Common Data Form version 4 (NetCDF4) (http://www.unidata.ucar.edu/software/netcdf/). Recently, a benchmark run on the $\mathrm{K}$ computer has achieved $10 \%$ of the peak performance using five nodes (40 cores), and usage has been verified with 81,920 nodes $(655,360$ cores). Furthermore, a subkilometer mesh global domain simulation (Miyamoto et al. 2013) was executed with a performance of 230 Tflops in double precision for 68 billion grid cells while using 20,480 nodes of the $\mathrm{K}$ computer. 


\section{Table 2 Timeline of the development of NICAM}

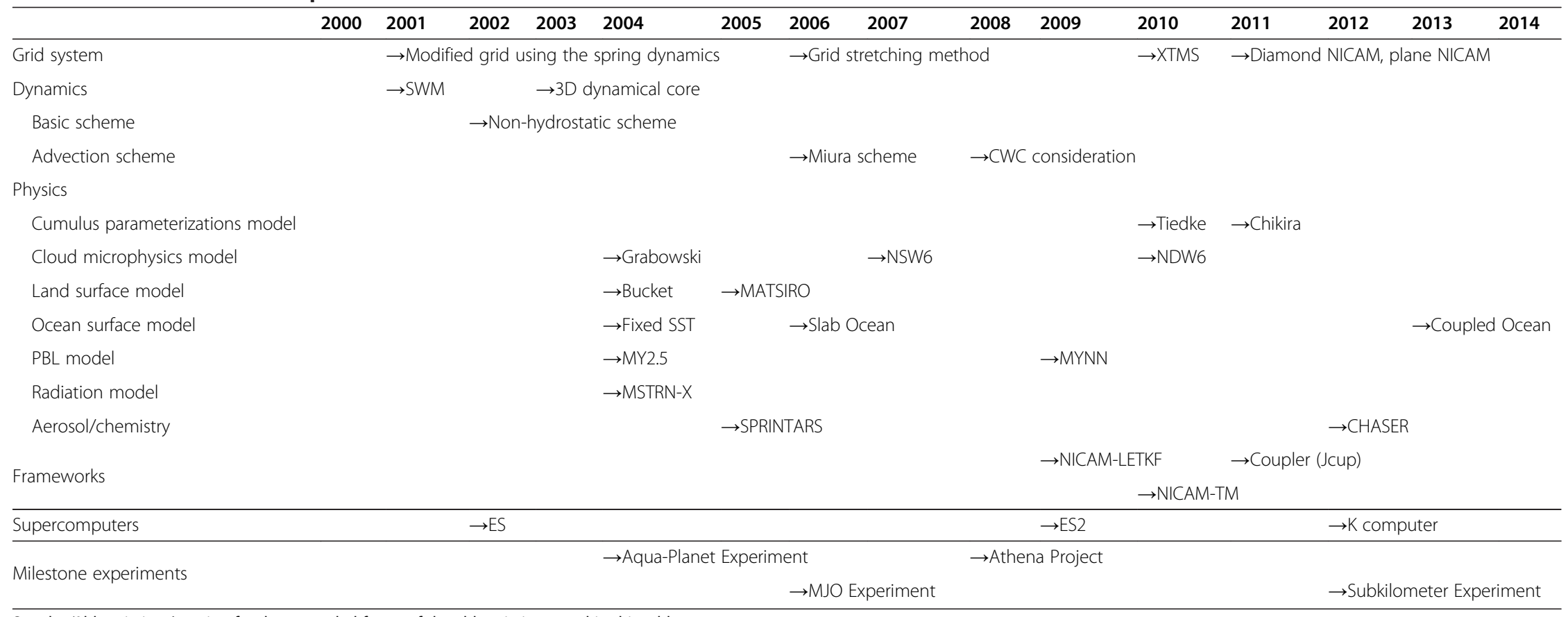


Further information on the NICAM development team and the initial developments can be found at http://nicam. jp. NICAM team members consist of researchers belonging to several research institutions in Japan. The source code is primarily written in Fortran 95 and follows the Meteorological Research Institute/Japan Meteorological Agency (MRI/JMA) standard coding rule (Muroi et al. 2002). The program is parallelized using Message Passing Interface (MPI) process parallelization via automatic compiler thread parallelization. OpenMP is not actively used as the current program. Each component is managed as one or more modules. In order to maintain readability of the source code, $C$ preprocessor macros are not used. The source code has been managed at repositories using the Concurrent Versions System (CVS), and the NICAM development team is currently moving to multi-branch development using the Git distributed revision control and source code management system. Due to its flexible portability, NICAM can run on various computer platforms, such as Earth Simulator, the K computer, IBM AIX, Linux, and Mac OSX. We have also tested several combinations of MPI libraries and Fortran compilers.

NICAM is also used as a benchmark program or a test platform for new architectures. For this purpose, we have released the dynamical core of NICAM as open source software (NICAM-DC), which is distributed under the terms of the Berkeley Software Development (BSD) 2-Clause License and is available for download (http://scale.aics.riken.jp/nicamdc/). The NICAM development team also participates in a working group for the common base library environment of weather and climate models and in cooperative development efforts with other modeling groups in Japan. In the field of computational science, NICAM has made significant contributions as a benchmark program and is one of the main application programs used in Exascale computing research.

\section{Dynamics}

\section{Grid configuration and advection scheme}

As reviewed in the 'Introduction' section, the use of grid models with finite-difference and finite-volume methods for weather and climate models was reconsidered as massively parallel computer architectures entered widespread use. An icosahedral grid is a globally quasi-uniform and is possibly the most suitable base for the development of an atmospheric model that can be run on a supercomputer. Additionally, the adoption of an icosahedral grid for the horizontal grid of NICAM was partially motivated by the results of Heikes and Randall (1995), in which a twodimensional (2D) shallow water system model was developed using the Z-grid arrangement of the prognostic variables (Randall 1994; Figure 4d), which followed Masuda and Ohnishi (1986). The Z-grid model, however, had a disadvantage in that the model needed to diagnose the velocity fields from the vorticity and divergence fields by solving two Poisson equations in each time step. Furthermore, it was not obvious that an efficient Poisson solver would become available for use on the massively parallel computers, at least when the NICAM development began.

Tomita et al. (2001) did not follow any previous study (such as Heikes and Randall 1995; Masuda and Ohnishi 1986) and instead examined a new method by using the Arakawa A-grid (Arakawa and Lamb 1977), which located prognostic variables (fluid depth and velocity) at the same nodes (Figure 4a) and thus did not require Poisson solvers. The accuracy and stability of the shallow water model were improved after applying a grid optimization that is now commonly known as 'spring dynamics' (Tomita et al. 2002), and the physical performance of the model was evaluated using the standard tests provided in Williamson et al. (1992). The methods used to discretize the horizontal gradient, divergence, rotation, and Laplacian operators in NICAM are similar to those described in Tomita et al. (2001) and Tomita and Satoh (2004), except for some minor updates in the passive tracer transport (Miura 2007; Niwa et al. 2011a) and damping operators.

When the model was first developed by Tomita et al. (2005), NICAM was capable of producing a global simulation with horizontal grid spacing of $3.5 \mathrm{~km}$. It was also the first model to produce a global simulation with horizontal grid spacing of less than $1 \mathrm{~km}$ (Miyamoto et al. 2013). These characteristics indicate that the A-grid arrangement is a good choice due to its simplicity and the relative ease with which it attains high computational performance on Earth Simulator and the K computer. It should be noted that Tomita et al. (2001) provided the first example of the shallow water model on an icosahedral grid, which uses the finite-volume method and adopts velocity components as prognostic variables. However, it is well known that the A-grid model is unsuitable for simulations of inertia-gravity waves and geostrophic adjustments and that the model suffers from grid-scale noise (Randall 1994). Therefore, other options should be considered for the horizontal variable arrangement, such as those described below.

The disadvantages of the B/ZM-grid (Figure $4 \mathrm{~b}$ ) and $\mathrm{C}$-grid (Figure $4 \mathrm{c}$ ) arrangements, which were pointed out by Ničkovic et al. (2002), on the hexagonal grid were partially solved by Ringler and Randall (2002) and Thuburn et al. (2009), respectively. Although problems with the computational modes remain due to the mismatch of the degrees of freedom between the fluid depth/pressure and horizontal velocity, the B/ZM-grid and $\mathrm{C}$-grid not only allow a more realistic representation of inertia-gravity waves and geostrophic adjustments than 

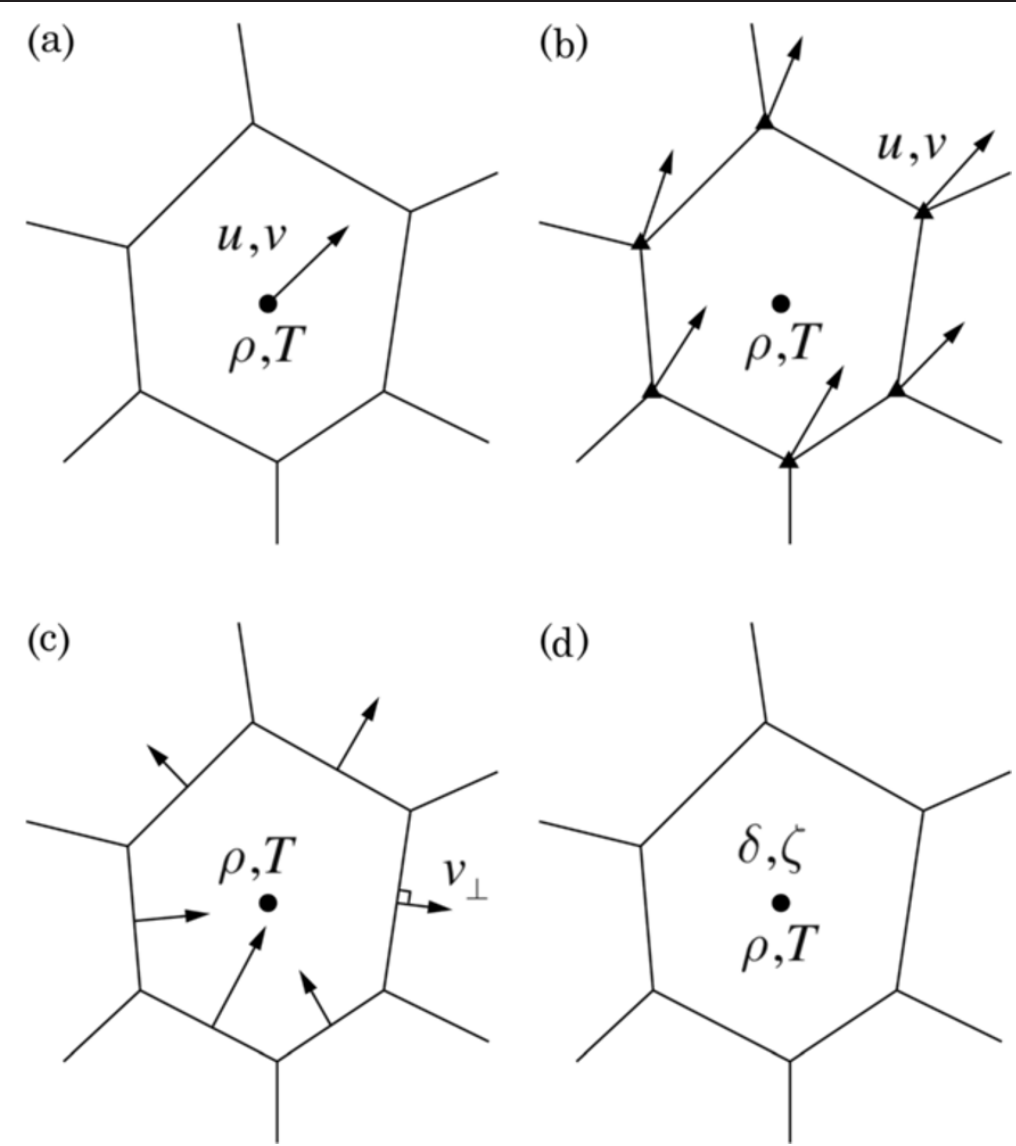

Figure 4 Arrangements of variables on the hexagonal grid. Arrangements of prognostic variables on the hexagonal grid for the (a) A-grid, (b) B/ZM-grid, (c) C-grid, and (d) Z-grid staggering. The symbols $\rho, T, u, v, v_{\perp}, \delta$, and $\zeta$ refer to density, temperature, zonal components, and meridional components of the flow velocity, respectively, that is defined (a) at the center or (b) at the vertex of the hexagon, normal component of the flow velocity on each edge, divergence of the horizontal flow, and vertical component of vorticity.

the A-grid but also are free from the checkerboard pattern. Currently, we are investigating the $\mathrm{B} / \mathrm{ZM}$-grid as a candidate to replace the A-grid, and the difficulty in managing the computational mode has been largely eliminated by revising the operators of Ringler and Randall (2002). This activity is ongoing, and details of the improvements will be reported in forthcoming papers. The update of the dynamical core will also include the newly developed transport algorithms of Miura and Skamarock (2013) and Miura (2013).

\section{Vertical resolution issues}

NICAM adopts the Lorenz grid and $z^{*}$ (terrain-following) coordinates (Gal-Chen and Somerville 1975) as a vertical coordinate system (Figure 3 of Satoh et al. 2008). Density, horizontal velocity, and internal energy are defined at the full levels, and vertical velocity is defined at the half levels. In NICAM, $z^{*}$ is generally specified so as to linearly depend on the geometric height $z$ between the model surface and top (the linear- $z^{*}$ coordinate). Using the standard vertical levels $Z_{k}$, geometric height $z_{X, k}$ is formulated as

$$
z_{X, k}=Z_{k}+\left(1-\frac{Z_{k}}{H_{\text {top }}}\right) Z_{X, s f c}
$$

where $k$ is an index for the vertical level, $X$ represents the location of the horizontal grid, and $H_{\text {top }}$ and $Z_{X, s f c}$ are the heights of the model top and bottom, respectively. In general, $H_{\text {top }}=40 \mathrm{~km}$ is used with 40 vertical levels. For standard cases, the lowermost full level is located at $81 \mathrm{~m}$. The vertical interval of the half-level $\Delta Z_{k}$ increases with height, from $\Delta Z_{k}=170 \mathrm{~m}$ at the bottom, $\Delta Z_{k}<1 \mathrm{~km}$ below $10 \mathrm{~km}$, and $\Delta Z_{k} \sim 3 \mathrm{~km}$ near the model top.

In some situations, the hybrid- $z^{*}$ coordinate (Simmons and Burridge 1981) is employed to reduce the amount of 
pressure gradient force numerical errors that arise from topography. It is formulated as

$$
z_{X, k}=Z_{k}+\left(\frac{\sinh \frac{H_{\text {top }}-Z_{k}}{H_{\text {efold }}}}{\sinh \frac{H_{\text {top }}}{H_{\text {efold }}}}\right) Z_{X, s f c},
$$

where $H_{\text {efold }}$ is a height scale parameter (e.g., $H_{\text {efold }}=$ $10 \mathrm{~km}$ ). In the hybrid-z* coordinate, intervals of the vertical level approach those of the standard vertical level for $Z_{k} \gg H_{\text {efold }}$, whereas in the linear- $z^{*}$ coordinate, it is constant with height even near the model top. This hybrid $-z^{*}$ coordinate advantage is obtained at the expense of packing more vertical levels just above the higher mountain, which may cause the vertical CFL condition to become a serious issue for the hybrid $-z^{*}$ coordinate. Klemp (2011) also proposed a hybrid approach, in which the coordinate surfaces are smoothed with height in order to remove smaller scale terrain structures from the surfaces.

Recently, we constructed a new configuration for the vertical levels of NICAM in order to perform simulations with finer vertical resolutions in the troposphere, stratosphere, and mesosphere levels. The development of this 'middle atmosphere NICAM' is motivated by the results of recent climate studies in which the tropospheric circulations were found to be affected by the stratosphere. It should be noted that the inclusion of the middle atmosphere into a climate model is a worldwide trend in the climate model community, since it improves the reproducibility of the large-scale tropospheric circulation (e.g., Shindell et al. 1999). Currently, the middle atmosphere NICAM employs the hybrid- $z^{*}$ coordinate, and its model top height is set to $80 \mathrm{~km}$. The vertical intervals in the lower atmosphere are the same as the standard vertical coordinate. As the vertical interval increases with height and reaches a specific criteria $\left(\Delta z_{\max }\right)$, the vertical level is set with the uniform interval of $\Delta z_{\max }$ (except near the model top) in order to appropriately simulate the propagation of atmospheric gravity waves. We have tested $\Delta z_{\max }=2,1$, and $0.5 \mathrm{~km}$ with a horizontal resolution of g-level $7(\bar{\Delta}=120 \mathrm{~km})$, as shown in Figure 5. As the vertical resolution increases, the reproducibility of the zonal mean temperature and zonal wind tends to improve in the upper troposphere and middle atmosphere. Interestingly, westerly winds around the equatorial lower troposphere in June 2004 area only well simulated when the vertical resolution is set to $1 \mathrm{~km}$ or less. NICAM has an option that allows the deep atmosphere configuration (Tomita and Satoh 2004) to be switched. For the middle atmosphere simulations, the choice of the deep atmosphere is considered appropriate.

Determining the proper vertical coordinates is an ongoing issue for high-resolution non-hydrostatic models.
For global non-hydrostatic models in particular, the numerical instability of the terrain-following coordinates becomes more severe because the steep topography over the Andes or the Antarctica is within the simulation domain. For the present simulations, relatively coarser topographic data were used by applying a smoother for the NICAM simulations. For example, for the $3.5 \mathrm{~km}$ mesh simulations, $14 \mathrm{~km}$ mesh coarsened topographic data were generally used. In addition, a minimum threshold value of the Brunt-Väisälä frequency was specified for the calculations in the PBL schemes, that is and the Mellor-Yamada Nakanishi-Niino (MYNN) scheme, in order to suppress an unusual increase in vertical shears near the surface.

To overcome the problem of terrain-following coordinates, different candidates have been proposed. For example, the possibility of a vertical coordinate that is based on geopotential height, i.e., the $z$-coordinate, has been investigated. Although this approach is common for ocean models (Adcroft et al. 1997), it must be understood that the implementation of the $z$-coordinate to non-hydrostatic atmospheric models is not straightforward (Gallus and Klemp 2000). The immersed boundary method is well known for computational fluid dynamics (Mittal and Iaccarino 2003). Various approaches to overcome the problems of the $z$-coordinate were taken into consideration, such as the cut-cell method or the thin-wall approximation (e.g., Bonaventura 2000; Steppeler et al. 2002, 2006; Yamazaki and Satomura 2008, 2010), have been taken into consideration. We plan to introduce such an option for the $z$-coordinate of NICAM in the near future.

\section{Physics}

\section{Cloud microphysics schemes}

Cloud microphysics can be used to solve the growth equations of a single hydrometeor particle. The related processes are mainly categorized into four components: nucleation processes, phase change, collisional processes, and gravitational sedimentation. These processes have not been calculated explicitly and have been parameterized in conventional AGCMs since the characteristic timescale of these processes and spatial variability of cloud ensembles cannot be resolved using the time-step and grid resolution of GCMs. Global non-hydrostatic models operate by calculating these processes via cloud microphysics schemes in order to explicitly evaluate time evolution of cloud growth over the global domain. The implemented schemes are generally developed for regional non-hydrostatic models. This section introduces cloud microphysics models that are applicable to global non-hydrostatic models. For a more fundamental theoretical basis of cloud microphysics processes, refer to Pruppacher and Klett (1997). 


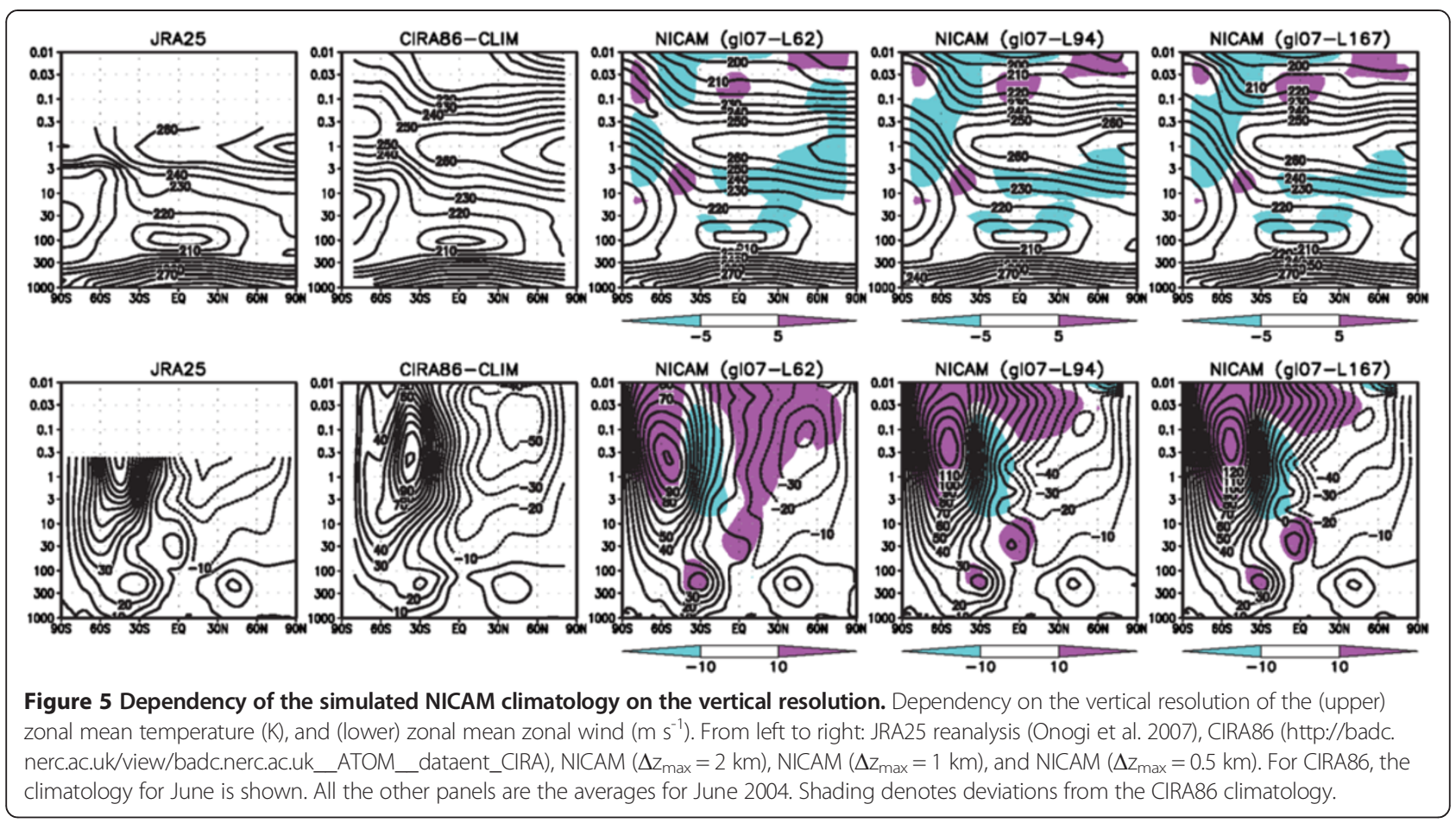

Multi-moment bulk method Hydrometeor particles typically have a radius $r$ from $10 \mu \mathrm{m}$ to $1 \mathrm{~mm}$ and populations from $10^{2}$ to $10^{9} \mathrm{~m}^{-3}$. To manage numerous particles efficiently (in terms of computational cost), cloud microphysics modeling generally assumes that particles with the same radius are homogeneously distributed within a grid cell of the model and develop in the same manner while under the same environmental conditions. Growth equations of hydrometeor particles with similar radii are solved together and the particle size distribution (PSD) $f(r)$, which is the number density sorted by the radius of the hydrometeors, is then predicted. $\mathrm{Nu}$ merous observational studies have shown that liquid hydrometeor particles have three major modes for the PSD (Pruppacher and Klett 1997): particles in the condensational growth mode (which have a mode radius around $10 \mu \mathrm{m})$, particles in the collisional growth mode (which have a mode radius larger than $100 \mu \mathrm{m}$ ), and the drizzling mode (which is a transitional mode between the two aforementioned modes).

There are two main methods that can be used to predict the time evolution of the PSD. One is the multimoment bulk method, which predicts the integrand of each mode by approximating the modes via the gamma distribution (e.g., Milbrandt and Yau 2005b; Seifert and Beheng 2006):

$$
f(r)=K r^{v} \exp \left(-\lambda r^{\mu}\right)
$$

where $\kappa, \lambda, \mu$, and $v$ are the diagnosed parameters. The $k$-th moment of the PSD, $M^{(k)}$, is defined as

$$
M^{(k)} \equiv \int_{0}^{\infty} f(r) r^{k} d r
$$

and the time evolution of the prognostic moments is evaluated by integrating the growth rates of a single hydrometeor particle over the entire range of the PSD (e.g., Seifert and Beheng 2006). The other is the spectral bin method, which solves growth equations by discretizing the PSD with tens of bins covering these modes (Khain et al. 2000, 2008). Because of their computational efficiency, the multi-moment bulk methods are widely used for 3D non-hydrostatic simulations.

The multi-moment bulk method is categorized by the number of its prognostic moments: the single-moment bulk method predicts the mass concentration of hydrometeors (Kessler 1969; Lin et al. 1983; Rutledge and Hobbs 1983; Walko et al. 1995; Grabowski 1998; Hong et al. 2004; Thompson et al. 2008; Tomita 2008b), and the double-moment bulk method predicts the number concentration in addition to the mass concentration (Meyers et al. 1997; Feingold et al. 1998; Morrison et al. 2005; Seifert and Beheng 2006; Phillips et al. 2007; Morrison and Gettelman 2008; Lim and Hong 2010).

The four parameters used to represent the PSD $(\kappa, \lambda, \mu$, and $v$ ) are diagnosed by prognostic moments. Hence, as the number of the prognostic moments is increased, a 
variety of PSD shapes can be represented. For example, increases in the mode radius and skewness of the PSD are observed in collisional growth (Berry and Reinhardt 1974). These distortions of the PSD are important for initiation of precipitation (Seifert and Beheng 2001). Furthermore, once precipitation occurs, the gravitational sedimentation of the hydrometeor particles induces further distortion of the PSD due to the gravitational size sorting mechanism and the time evolution of the PSD affects the subsequent chain of particle growth (Wacker and Seifert 2001; Milbrandt and Yau 2005a; Milbrandt and McTaggart-Cowan 2010). In addition, higher order moments are required for the closure of the governing equations in the collisional processes (e.g., Seifert and Beheng 2001). Thus, an increase in the number of prognostic moments is linked to improvements in the time evolution of the PSD and complexity of the cloud microphysics modeling. Additionally, complexity and calculation costs increase as the number of prognostic moments increases.

For climate studies, collisional processes are particularly important to the radiative budget because such processes dominate the persistence of warm-phase clouds due to the rapid growth rate of cloud droplets during the precipitating process, along with the strong cloud albedo perturbations caused by the spatial and temporal variabilities of their growth rates (Albrecht 1989; Lohmann and Feichter 2005). The double-moment bulk method enables us to explicitly evaluate the dependence of the collisional growth rate on the mode radii (Berry and Reinhardt 1974; Feingold et al. 1998; Khairoutdinov and Kogan 2000; Seifert and Beheng 2001). In addition, cloud radiative forcing can be more accurately estimated because the cloud optical properties are calculated using the mass concentration and number concentration (Hansen and Travis 1974). In contrast, the single-moment bulk method assumes that the radii of the hydrometeors are empirical values. Empirical values do not reproduce the temporal and spatial variability of atmospheric states, and their validity has not been confirmed for various types of climate change, such as global warming conditions. The triple-moment bulk method, which was recently developed and used (Milbrandt and Yau 2005a, b; Seifert 2008; Shipway and Hill 2012), predicts or diagnoses the radar reflectivity factor in addition to the aforementioned two moments and is applied to the regional simulations of severe storms (Milbrandt and Yau 2005a, 2006). Of course, the higher order moment bulk methods also contain empirical formulations and parameters that can be used to calculate cloud growth and optical properties. However, previous process studies have shown that the differences of simulated results between double-moment and triple-moment bulk methods are smaller than those between single-moment and double-moment bulk methods (e.g., Milbrandt and Yau 2005a; Shipway and Hill 2012). In addition, it has also been demonstrated that a welloptimized double-moment method can capture the characteristics of cloud growth simulated by a spectral bin method (Seifert and Beheng 2001; Seifert et al. 2006; Seifert 2008; Milbrandt and Yau 2005a, 2006). These facts indicate that the double-moment bulk method is practical and applicable in terms of cost performance of numerical simulations.

Cloud microphysics schemes in NICAM NICAM initially adopted a single-moment bulk cloud microphysics scheme that was proposed by Grabowski (1998) in order to explore the multi-scale interaction of moist convective systems because the organizations of deep convective systems do not depend on the details of cloud microphysics schemes. Instead, meso-scale circulations are reproduced if the latent heat release in updrafts and the evaporation cooling caused by rain drops are considered by predicting the mass concentration of hydrometeor particles, as introduced in the single-moment bulk scheme. In the latest version, the schemes proposed by Kessler (1969), Lin et al. (1983), Hong et al. (2004), and Tomita (2008b) are implemented. In particular, NICAM single-moment scheme with six water categories proposed by Tomita (2008b) (hereinafter, referred to as NSW6) has been well evaluated by comparisons with satellite observations (Satoh et al. 2010; Kodama et al. 2012; Hashino et al. 2013; Roh and Satoh 2014) and, hence, is used by default. Because of the relatively low calculation cost, the use of single-moment schemes enables us to conduct very highresolution global non-hydrostatic simulations at g-level 13 $(\bar{\Delta}=870 \mathrm{~m}$; Miyamoto et al. 2013), or for longer integrations up to several decades.

Recently, Seiki and Nakajima (2014) implemented a double-moment bulk cloud microphysics scheme (NICAM double-moment scheme with six water categories; hereinafter, referred to as NDW6) into NICAM. Seiki et al. (2014) demonstrated that the NDW6 scheme well reproduces cloud radiative forcing by calculating cloud ice number concentration with using accurate databases of the cloud optical properties. Figure 6 shows the simulated cloud optical thickness (COT) and outgoing shortwave radiative flux at the top of the atmosphere that were obtained using the NDW6 scheme, along with the observed outgoing shortwave flux at the top of the atmosphere that was obtained from the satellite product of CERES SYN1deg_Ed3A (Wielicki et al. 1996; Kato et al. 2011). The simulation showed that convective clouds with a high COT were scattered over the tropics and formed regional cloud clusters (e.g., over the central Pacific). For example, Typhoon Fengshen remained over the Philippines and high COT clouds were distributed along its vortical structure. Furthermore, synoptic scale disturbances were 

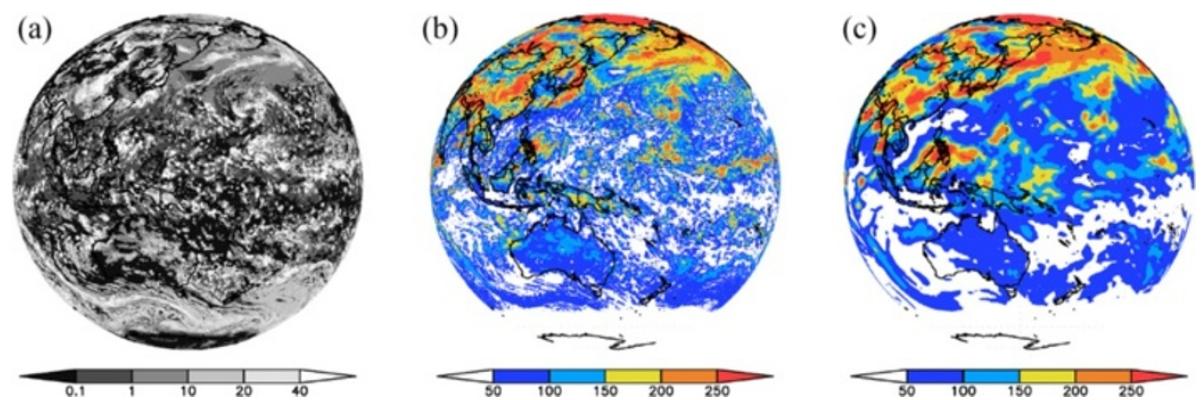

Figure 6 Simulated results for the $\mathbf{1 4} \mathrm{km}$ mesh NICAM with the double-moment cloud microphysics scheme. Simulated results for the double-moment cloud microphysics scheme for the $14 \mathrm{~km}$ mesh NICAM on 20 June 2004: (a) simulated cloud optical thickness at a wavelength of $550 \mathrm{~nm}$ at 00:00 UTC, (b) daily averaged outgoing shortwave flux $\left(\mathrm{W} \mathrm{m}^{-2}\right)$ at the top of the atmosphere, and (c) the daily averaged outgoing shortwave flux $\left(\mathrm{W} \mathrm{m}^{-2}\right)$ at the top of atmosphere, as produced by the CERES SYN1deg_Ed3A product.

organized over the mid-latitude regions and optically thick regions were located along the front. A shortwave flux corresponding to these high COT regions was largely reflected by clouds. These features agree well with the satellite observation. As shown by the NDW6 scheme, the impact of the cloud radiative forcing, which results in improvements to the climatological biases in NICAM, should be evaluated in future studies.

\section{Subgrid-scale turbulence of the planetary boundary layer}

Boundary layer turbulence plays an important role in driving large-scale circulations of the atmosphere as it transports heat upward from the Earth's surface in the form of sensible and latent heats, which are converted from incoming solar energy at the surface (Trenberth et al. 2009). To simulate atmospheric circulations, a parameterization scheme that computes the effects of such turbulent transport in the subgrid scale of a numerical model needs to be incorporated, unless the resolution is high enough to resolve turbulence.

NICAM adopts the MYNN scheme, which is a modified version of the original Mellor-Yamada (MY) model (Mellor and Yamada 1982; Nakanishi and Niino 2006, 2009), for such turbulent transport models (Noda et al. 2010). There are three major advantages to employing the MY-type model: 1) the MY-type model can consistently and simultaneously compute subgrid-scale condensation and resultant turbulent fluxes by assuming the probability density functions regarding the inhomogeneity of temperature and water on a subgrid scale, 2) the model can consistently evaluate the impacts of the differences of turbulent moments, and 3) the model can run with low computational cost because it omits minor terms in the turbulent transport equation system. Based on the degree of approximation from the original equations, level 1 to level 4 can be included in the MY-type model. The level-2, level-2.5, and level-3 MYNN version models are installed in NICAM, and the level-2 model is used as a standard PBL scheme.
Figure 7 compares the impacts of these different level models on the spatial distributions of simulated clouds. As can be seen in the figure, all turbulent models properly simulate the spatial characteristics of, for example, high and mid-level clouds, even though the magnitude of the high clouds tends to be larger than those seen in satellite observations. For low clouds, the level- 2 model properly represents the characteristics of the regional contrast between a clear and cloudy sky, such as those seen over the eastern and western regions of the Pacific Ocean. Conversely, the low clouds that systematically develop along and off the Peruvian coast are not simulated well. Compared with the results of the level-2, level-2.5 and level-3 models produce a much smaller fraction of low clouds. It is speculated that these two models calculate more vertical turbulent heat transports of heat from the boundary layer to the free atmosphere, which results in a less humid boundary-layer state.

Due to the remarkable progress of computational technology, the model resolution of NICAM is steadily being increased, with the highest resolution to date having been achieved when a horizontal mesh size of $870 \mathrm{~m}$ was used (Miyamoto et al. 2013). For a global non-hydrostatic model, boundary-layer scale turbulence becomes explicitly and partially calculatable around this resolution, but will not be sufficiently resolved until the mesh size is less than $100 \mathrm{~m}$ (Khairoutdinov et al. 2009; Moeng et al. 2009). It is a challenging issue to parameterize turbulent transport processes in such an intermediate resolution (Wyngaard 2004), and continuous efforts are needed to improve the subgrid-scale turbulence parameterization schemes along with shallow cumulus convection.

\section{Radiation}

Atmospheric radiative transfer models calculate heating rates in the atmosphere and radiative flux at the Earth's surface using the 3D distribution of clouds/gases/aerosols and land/ocean surface properties with the atmospheric state. NICAM adopts the broadband radiative transfer 


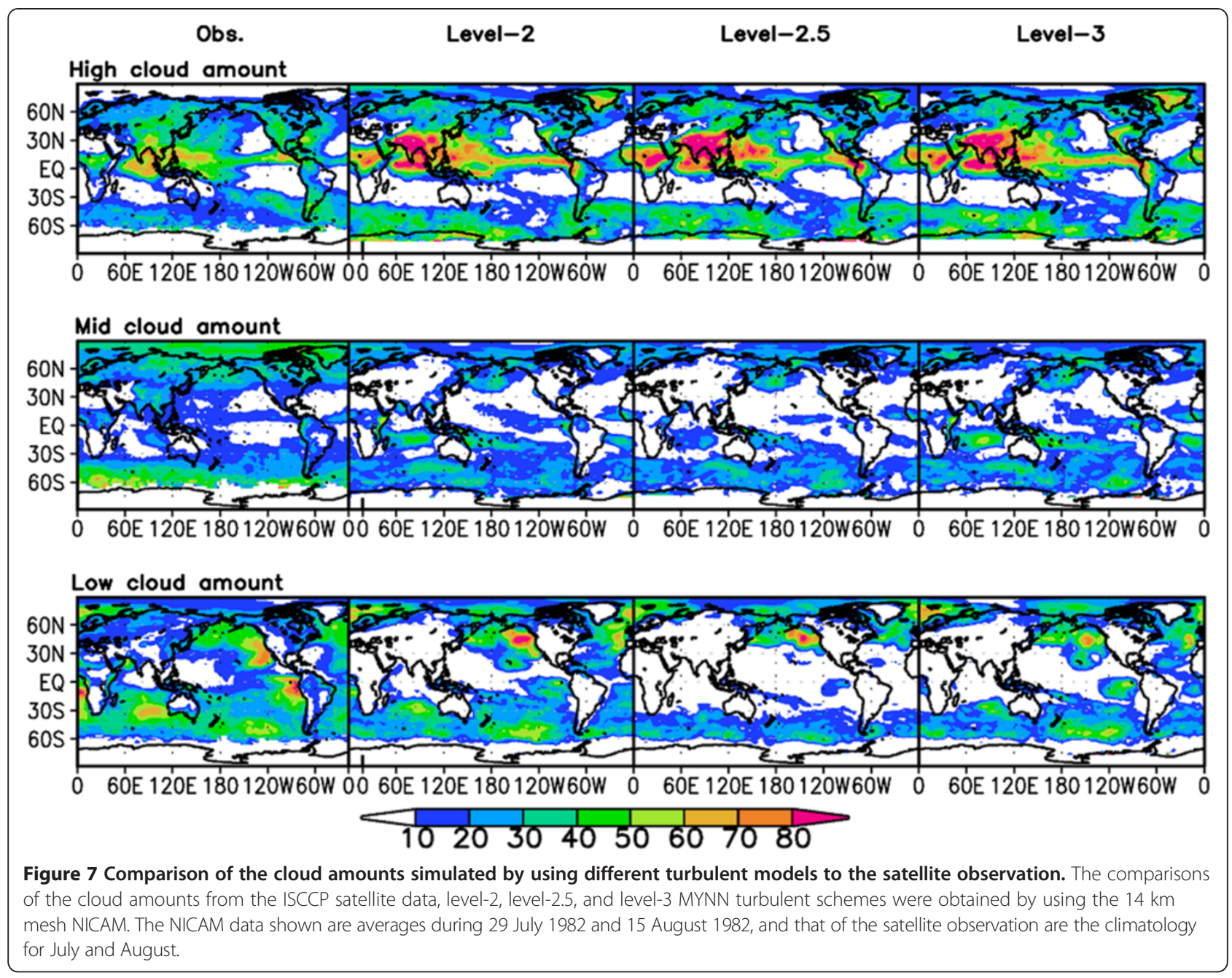

model 'MSTRN', which is based on the discrete ordinate method with a delta two-stream approximation and the correlated $k$-distribution method. The MSTRN model calculates gas absorption $\left(\mathrm{H}_{2} \mathrm{O}, \mathrm{CO}_{2}, \mathrm{O}_{3}, \mathrm{~N}_{2} \mathrm{O}, \mathrm{CH}_{4}\right.$, and $\left.\mathrm{O}_{2}\right)$ and the scattering/absorption of hydrometeors and aerosols (dusts, sea salts, carbonaceous, and sulfates) over an arbitrary time interval and then outputs short- and longwave radiation fluxes. A basic description of this model is written in Nakajima et al. (2000). In the latest package, 'MSTRN-X' (Sekiguchi and Nakaima 2008), the gas absorption processes are improved and successfully used to reduce the error of the heating rate. The scheme was introduced into NICAM through the AGCM version implemented for MIROC from the original one-dimensional (1D) model. The calculation of solar insolation (Berger 1978) was added to the AGCM version. The other cloud overlapping method (maximum-random overlapping) was incorporated since this version of the radiation scheme was included in MIROC3.2 (Hasumi and Emori 2004).

The calculation cost of the radiation scheme is very high in the AGCM, because both computing speed and precision are required for the scheme. The latest MSTRN$\mathrm{X}$ scheme improved the optimization method in order to reduce the integration points in the correlated $k$-distribution approximation without decreasing accuracy. In the NICAM default setting, the spectrum between 0.2 and $200 \mu \mathrm{m}$ is divided into 29 spectral bands with 111 integration points. Cloud-radiation feedback is one of the most important issues in the study of climate change. The high-resolution experiments performed by NICAM have an advantage in that they reduce the uncertainties of the horizontal/ vertical cloud distributions. In the recent studies described above, both the cloud scheme and radiation scheme are improved by considering the detailed size distribution of the hydrometeors and non-sphericity of the ice particles. This cooperative development of the cloud and radiation schemes will facilitate improvements in the future development of aerosol and chemistry modules (see 'Aerosol and chemistry modules' section).

NICAM also introduces the ISCCP simulator (Klein and Jakob 1999; Webb et al. 2001), with which the distribution of every cloud category can be calculated online. 
The results from the simulator have been used in numerous studies (Iga et al. 2007a; Suzuki et al. 2008; Collins and Satoh 2009; Noda et al. 2010; Sohn et al. 2010; Satoh et al. 2012b; Miyamoto et al. 2013; Tsushima et al. 2014). In some studies, new satellite simulator packages have been applied offline to the NICAM dataset. Kodama et al. (2012) used a series of satellite simulators that were part of the Cloud Feedback Model Intercomparison Project (CFMIP) Observation Simulator Package (COSP) (Bodas-Salcedo et al. 2011), and Hashino et al. (2013) used the Joint Simulator for Satellite Sensors (J-simulator). Therefore, the online use of these packages should also be taken into consideration.

\section{Aerosol and chemistry modules}

Currently, NICAM is implemented with a global 3D aerosol transport-radiation model, the Spectral RadiationTransport Model for Aerosol Species (SPRINTARS) (described fully in Takemura et al. 2000, 2002, 2005, 2009; Goto et al. 2011a). The SPRINTARS module predicts the mass mixing ratios of the main tropospheric aerosol species, i.e., carbonaceous (black carbon and organic matter), sulfate, soil dust, sea salt, and the precursor gases of sulfate (sulfur dioxide and dimethylsulfide (DMS)). The aerosol transport processes include emission, advection, diffusion, sulfur chemistry, wet deposition, dry deposition, and gravitational settling. Emissions of soil dust, sea salt, and DMS are calculated using the internal state of the model, whereas the emissions for the other primary aerosols and the distributions of oxidants (hydroxyl radical, ozone, and hydrogen peroxide) for the sulfur chemistry are prescribed by externally assumed data. In the module itself, meteorological fields such as clouds and precipitation, which are critical to determining aerosol lifetimes, are provided from the outer module after the cloud microphysics calculations are computed at each time step. In contrast, the calculated mass mixing ratios of the aerosols in each grid cell are calculated by the aerosol module SPRINTARS and then returned back to the outer module. In addition, aerosol variables are forwarded to the radiative transfer module, MSTRN-X (Sekiguchi and Nakaima 2008), in order to represent the direct aerosol effects, and also to cloud schemes such as NSW6, to represent the indirect aerosol effects.

SPRINTARS, which was originally coupled to MIROC (Watanabe et al. 2010) with a low spatial resolution of 100 to $300 \mathrm{~km}$, has compared well with various measurements (Goto et al. 2011a, b, 2012) and other global aerosol models participating in the AeroCom international project (e.g., Kinne et al. 2006). The results of the SPRINTARS module coupled to NICAM were also shown to generally agree with the satellite observations of aerosols and clouds for versions based on low spatial resolution of g-level $5(\bar{\Delta}=220 \mathrm{~km}$ ) (Dai et al. 2014a, b; Goto 2014) and high spatial resolution of g-level 10 $(\bar{\Delta}=7 \mathrm{~km})$ (Suzuki et al. 2008). Using Earth Simulator, Suzuki et al. (2008) conducted a global simulation with the finest resolution to date and showed the global aerosol and cloud distributions for July 2006 (Figure 8). Most of the aerosol plumes were in generally good agreement with the satellite observations, except for North America, Australia, and most remote oceans. Especially, over North America, the values of NICAMsimulated aerosol optical thickness were underestimated, possibly because of insufficient emissions from biomass burning and anthropogenic sources, or the lack of secondary organic aerosols formed from isoprene in forests (Henze and Seinfeld 2006). Through the aerosol-cloud interaction, the cloud droplet effective radius generally decreases, as the aerosol optical thickness increases, which were generally captured by both NICAM and MODIS. The cloud droplet effective radii simulated by NICAM were smaller than those obtained from MODIS, probably because those retrieved from $2.2 \mu \mathrm{m}$ (shown in Figure 8) correspond to those captured below the cloud top heights where the cloud droplet effective radii are larger than those at cloud top height (Nakajima et al. 2010). Very recently, regional aerosol simulations that used the stretched grid system with a high spatial resolution of approximately $10 \mathrm{~km}$ were performed for the Kanto region of Japan under the MEXT/RECCA/SALSA project (SALSA 2014; Goto et al. 2014). These simulations were carried out at relatively low computational cost by using two supercomputers at the University of Tokyo (SR16000 and FX10).

The CHASER atmospheric chemistry module has also been implemented into NICAM (SALSA 2014). This module primary focuses on tropospheric chemistry while considering the chemical cycle of $\mathrm{O}_{x}-\mathrm{NO}_{x}-\mathrm{HO}_{x}-\mathrm{CH}_{4}-\mathrm{CO}$ relation to the oxidation of volatile organic compounds (VOCs) and halogen chemistry in order to calculate the concentrations of 92 chemical species with 262 chemical reactions (58 photolytic, 183 kinetic, and 21 heterogeneous reactions) (Sudo et al. 2002a, b; Watanabe et al. 2011). Using the CHASER module, the mixing ratios of atmospheric gases, which mainly include ozone, $\mathrm{NO}_{x}, \mathrm{CO}$, $\mathrm{SO}_{2}$, VOCs, and sulfate aerosols, can be predicted. The transport processes of the chemical tracers include emission, advection, diffusion, chemical reaction, wet deposition, and dry deposition. The emissions of lighting $\mathrm{NO}_{x}$ and DMS are calculated by using the internal parameters of the model, whereas the emissions of the other gases are prescribed. The photolysis rates are calculated online by using the temperature and radiation fluxes computed in the radiative transfer module. Like the aerosol module, the meteorological field information is input from the outer module after the cloud 
(a) MODIS AOT

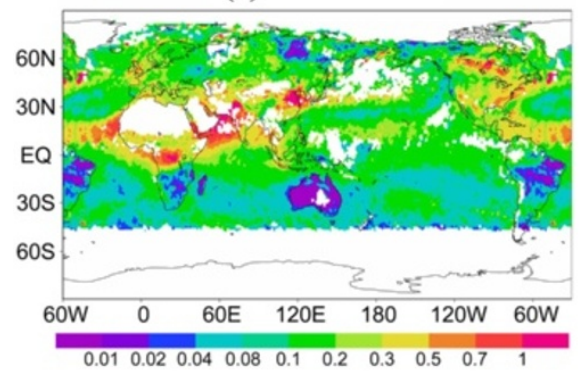

(c) NICAM-SPRINTARS AOT

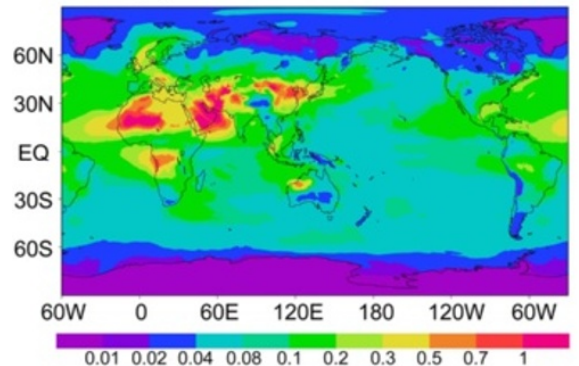

(b) MODIS Effective Radius

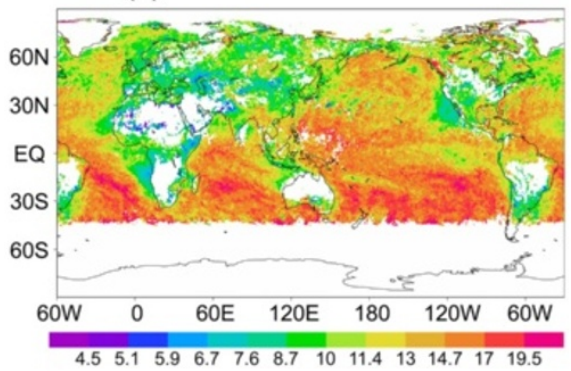

(d) NICAM-SPRINTARS Effective Radius

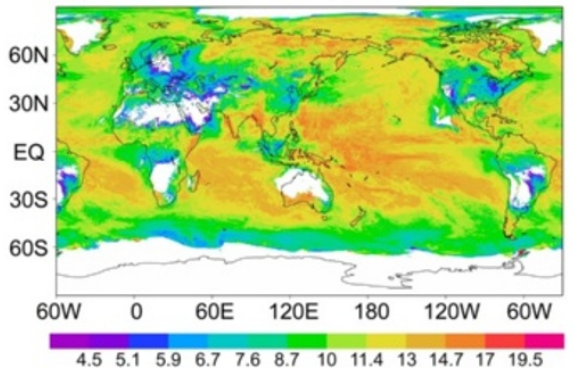

Figure 8 Distributions of aerosol optical thickness and cloud droplet effective radius from the NICAM-SPRINTARS simulations. Global geographical distributions of $(a, c)$ aerosol optical thickness and $(b, d)$ cloud droplet effective radius from $(c, d)$ the NICAM-SPRINTARS simulations in comparison to those obtained from (a, b) the MODIS satellite observations for 1 to 8 July 2006 (cited from Suzuki et al. 2008). The unit of cloud droplet effective radius is micrometers.

microphysics calculations and to the chemistry module at each time step. In contrast, the calculated mass mixing ratios of the tracers in each grid cell within the chemistry module are returned back to the outer module. In addition, ozone, $\mathrm{N}_{2} \mathrm{O}$, and $\mathrm{CH}_{4}$ are calculated online and used in the radiative transfer module to represent the atmospheric warming effects.

The distributions of the trace gases obtained by CHASER, which is currently coupled to MIROC at a low spatial resolution of approximately $300 \mathrm{~km}$, are generally compared to the observations (Sudo et al. 2002b; Sudo and Akimoto 2007; Nagashima et al. 2010) and to other chemistry models under international model comparison projects such as the Atmospheric Chemistry and Climate Model Intercomparison Project (ACCMIP) (e.g., Lamarque et al. 2013). Under the MEXT/RECCA/SALSA project, the results of CHASER, along with the globally uniform and regionally stretched grid systems, were compared with the observations (SALSA 2014). Furthermore, the chemical module has been currently expanded to a fully coupled aerosol-chemistry module by coupling CHASER with SPRINTARS, as developed in Watanabe et al. (2011) and used by MIROC.

The unified module, consisting of the fully coupled aerosol-chemistry, coupled to NICAM (hereinafter referred to as NICAM-Chem) can explicitly consider various interactions between aerosols and gases, as shown in Figure 9. For example, as an aspect of the aerosol simulation, the unified module can precisely calculate the sulfate formation with online oxidants such as hydroxyl radicals and ozone, whereas SPRINTARS uses assumed oxidants. In contrast, as an aspect of short-lived gases, calculations of the heterogeneous reactions onto the aerosol surface are expected to provide the greatest advantage when using the unified model. In addition to the sophisticated interactions between aerosols and gases, the chemistry of nitrate will be implemented into NICAM-Chem by using a thermodynamic equilibrium condition and secondary organic aerosols (SOAs). As a result, the new unified chemistry module is expected to provide better distributions of aerosols and gases, and, in the near future, we expect to be able to provide such distributions globally with a high spatial resolution of less than $10 \mathrm{~km}$.

\section{Land model}

We implemented two land surface schemes in NICAM in order to calculate the water and energy balance over land. The first scheme is a simple bucket land surface model (Kondo 1993), and the other involves the minimal advanced treatments of surface interaction and runoff (MATSIRO) model (Takata et al. 2003). When used with NICAM, the simple bucket land surface model, which was first used by Miura et al. (2007a), has three vertical layers for predicting soil temperature and one layer for predicting the soil moisture. 


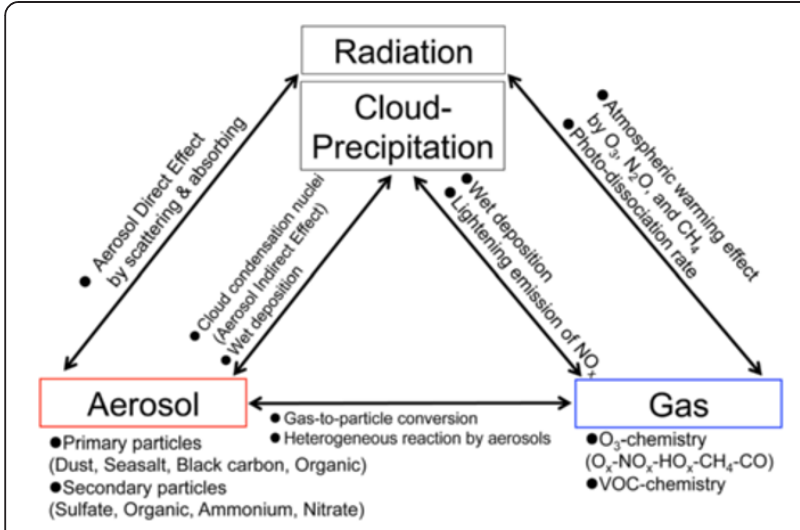

Figure 9 Relationship between the aerosol, gas, cloud, precipitation, and radiation fields for NICAM-Chem. Relationship between the aerosol, gas, cloud, precipitation, and radiation fields for the unified aerosol-chemistry module (NICAM-Chem). The aerosol and gas modules correspond to SPRINTARS and CHASER, respectively.

The MATSIRO scheme is the same as that originally employed in MIROC (Hasumi and Emori 2004). Kodama et al. (2012) were the first to use MATSIRO with NICAM. This scheme has five vertical layers for predicting soil temperature and soil moisture, as well as a snow scheme with thee vertical layers.

Even in a several-kilometer grid simulation, land use and land cover cannot be regarded as homogeneous in one grid cell if it is to be used to evaluate the land surface heterogeneities smaller than the horizontal grid scale. Accordingly, we are currently implementing a mosaic treatment of the land surface models in order to improve the accuracy of the water and energy fluxes at the land surface. We will also attempt to incorporate an urban canopy model in order to simulate the global urban energy balance.

\section{Assimilation \\ Local ensemble transform Kalman filter applied to NICAM: NICAM-LETKF}

The introduction of a data assimilation system into NICAM is a challenge because it might enable us to produce a high-resolution dataset with $\mathrm{O}(\mathrm{km})$ mesh size that can be used for improved better numerical simulations and research analysis. Data assimilation is an analysis technique that provides an accurate estimate of the atmospheric state by using observation data and model forecasts. It plays an important role in improving numerical weather prediction by providing an accurate initial condition. The ensemble Kalman filter (EnKF) is an advanced data assimilation method that uses flowdependent forecast error statistics that are represented by the ensemble prediction (Evensen 1994). For a linear system, the Kalman filter (KF) gives a minimum mean square error if the error is a Gaussian distribution (Kalman 1960). However, it is difficult to apply the KF because the computational cost for an atmospheric model with a high degree of freedom (order of $10^{7}$ ) is high. To resolve this problem, Evensen (1994) proposed the EnKF, which approximates the KF by using the forecast spread of the ensemble prediction. Furthermore, the local ensemble transform Kalman filter (LETKF) (Hunt et al. 2007) was developed based on the ensemble transform Kalman filter (ETKF) (Bishop et al. 2001) and used an algorithm that was designed for suitability with parallel computers by taking advantage of the independent local analyses of the local ensemble Kalman filter (LEKF) (Ott et al. 2004). For details on the mathematical formulation and implementation of these approaches, refer to each reference.

Previous studies have applied the LETKF to regional and global atmospheric models and have shown promising results (Miyoshi and Aranami 2006; Miyoshi and Yamane 2007). Kondo and Tanaka (2009) applied the LETKF to NICAM in order to develop NICAM-LETKF, which was the first LETKF to be applied to a global non-hydrostatic model. They then investigated the feasibility and stability of NICAM-LETKF using a perfect model and determined that the system works appropriately for a realistic nonhydrostatic model (NICAM). However, the horizontal resolution used in their study was not very high (g-level 5 or $\bar{\Delta}=220 \mathrm{~km}$ ), where the model would behave hydrostatically. Additionally, it is unclear whether NICAM-LETKF will work stably when real observations are used. Therefore, a future task will be to investigate data assimilation with a high-resolution global non-hydrostatic regime using real observations. This would not only contribute to an improvement in weather prediction but also to the research on multi-scale interaction, by using the product of the assimilation. We are now developing a version of NICAM-LETKF that will be based on the LETKF code that was developed and continuously improved by Miyoshi (e.g., Miyoshi and Kunii 2011) and are currently testing assimilation of precipitation data observed by satellites in order to obtain a fine-mesh precipitation database using the method proposed by Lien et al. (2013).

\section{NICAM-based transport model: NICAM-TM}

An accurate estimation of the past and current $\mathrm{CO}_{2}$ budget for the Earth's surface is needed for reliable predictions of carbon cycle changes under global warming conditions. Therefore, an inversion method coupled with a tracer transport model was used to estimate the spatial and temporal variations of $\mathrm{CO}_{2}$ sources and sinks based on observations of $\mathrm{CO}_{2}$ concentrations (e.g., Tans et al. 1990). In an inversion analysis, we quantitatively estimated regional $\mathrm{CO}_{2}$ fluxes by considering the a priori estimate and uncertainties of the $\mathrm{CO}_{2}$ fluxes, which were derived from our present understanding of $\mathrm{CO}_{2}$ 
source/sink mechanisms and uncertainties of observations (including model representative errors). This analysis is based on Bayesian theory and is similar to data assimilations for meteorological forecasts (Tarantola 2005). However, in contrast to the observations of meteorological parameters, $\mathrm{CO}_{2}$ concentrations are not sufficiently observed around the globe. Therefore, estimates of $\mathrm{CO}_{2}$ sources and sinks are not well constrained by actual observations and are extremely sensitive to model transport errors (e.g., Gurney et al. 2002).

In response to the need for an accurate transport model, Niwa (2010) developed the NICAM-based transport model (NICAM-TM). For transport simulations of $\mathrm{CO}_{2}$, NICAM has an advantageous property: consistency with continuity (CWC) (Jöckel et al. 2001; Gross et al. 2002). Under the CWC condition, the mass conservation and Lagrangian conservation of a tracer are simultaneously guaranteed; that is, the volume integral of mass is conserved and a constant specific mass of a tracer is maintained along flow trajectories. The ability to achieve the CWC property is attributed to the fact that NICAM uses the finite volume method for its meteorological field integration and performs tracer transport on a common dynamical frame (Niwa et al. 2011a). The tracer mass conservation is strictly required for analyses of the $\mathrm{CO}_{2}$ budget, which is the main target of inversion studies. Furthermore, the Lagrangian conservation property is imperative for $\mathrm{CO}_{2}$ because it is an abundantly existing tracer (the global average $\mathrm{CO}_{2}$ concentration was about $390 \mathrm{ppm}$ for 2013) and the concentration changes that are analyzed are very small (no more than a few tens of ppm).

NICAM-TM consists of online and offline transport models, as well as an adjoint model for the tracer transport. In the online model, tracer transport is calculated concomitantly but independently with the integration of the meteorological field. More specifically, the tracers other than those for water are passive. Compared to the online model, the offline model is computationally inexpensive because it only calculates the tracer transport by using meteorological data calculated by the online NICAM-TM and stored in a disk beforehand. The adjoint model was developed based on the offline model, which calculates the sensitivities to certain tracer variables backward in time. Because long-term and multiple simulations are required for the inverse calculation, NICAM-TM is currently run with a relatively lowresolution for $\mathrm{CO}_{2}$ transport simulations; for the most part, a resolution of g-level 5 or 6 is used. However, after conducting intercomparison experiments (Law et al. 2008; Patra et al. 2008; Niwa et al. 2011b), we found that the performances of $\mathrm{CO}_{2}$ transport obtained are comparable to those of other models. Generally, the modeled winds are nudged towards the analyzed data (e.g., JMA Climate Data Assimilation System (JCDAS); Onogi et al.
2007) in order to match the simulated $\mathrm{CO}_{2}$ concentrations to the observed concentrations.

Niwa et al. (2012) performed an inversion analysis by using the synthesis inversion method (Enting 2002) with NICAM-TM. This was the first inversion study in which aircraft data were extensively used to constrain the global and regional $\mathrm{CO}_{2}$ budgets. The aircraft data were obtained from the Comprehensive Observation Network for Trace Gases by Airliner project (CONTRAIL) (Machida et al. 2008; Matsueda et al. 2008; Sawa et al. 2012). By adding the CONTRAIL data (Figure 10a) to the conventionally used surface observation network, Niwa et al. (2012) successfully reduced uncertainties of the $\mathrm{CO}_{2}$ flux estimates for Asia. Moreover, this study revealed the existence of a strong summer uptake by the biosphere in South Asia (Figure 10b), where the $\mathrm{CO}_{2}$ observations from CONTRAIL in the middle to upper troposphere have a predominant constraint on the flux estimation. Because biosphere models have not shown such a strong summer uptake (Patra et al. 2013), Niwa et al. (2012) suggested the existence of some unknown mechanisms of the $\mathrm{CO}_{2}$ sources and sinks in this region. To further improve the $\mathrm{CO}_{2}$ inversion, a four-dimensional (4D) variational method system is now being developed by using the adjoint model of NICAM-TM. Using this system, a large amount of $\mathrm{CO}_{2}$ concentration data that have been recently available from regular aircraft observations and satellite observations (e.g., Greenhouse Gases Observing Satellite (GOSAT)) will be exploited to further constrain the estimates of $\mathrm{CO}_{2}$ sources and sinks.

\section{Models related to NICAM}

\section{Stretch NICAM and diamond NICAM}

As described in 'Grid configuration and advection scheme' section, NICAM was originally designed for use with an icosahedral grid, which covers a sphere of the Earth quasi-uniformly and has a grid system based on 10 large diamonds. As extensions to the original configuration, NICAM can also be applied to a non-uniform resolution distribution grid or a regional grid by changing the positions of the grid points, the total number of diamonds, or the topology of their combination.

NICAM can also be adapted to simulations that target a particular area. Two approaches to performing a partially high-resolution simulation are typically used with NICAM. One includes the stretched icosahedral grid system developed by Tomita (2008a). In this approach, the icosahedral grid is stretched using the Schmidt transformation method and the grid size becomes gradually finer as grid points are concentrated onto the area of interest. In the stretch NICAM, the inhomogeneity of the horizontal grid sizes requires resolution-dependent parameters for physical schemes if the global domain is of interest. However, if a limited region is of interest, 


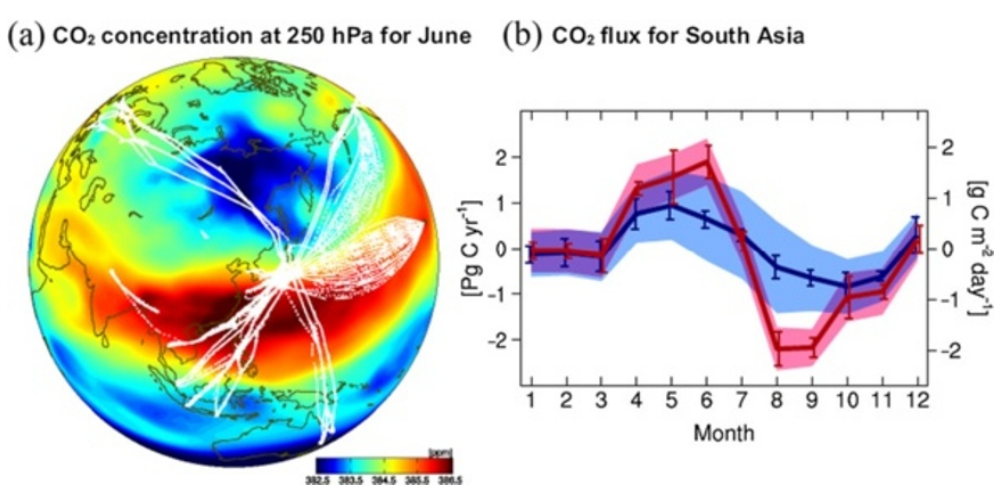

Figure 10 Simulated $\mathrm{CO}_{2}$ concentration field and monthly variation of the $\mathrm{CO}_{2}$ flux by NICAM-TM. (a) Mean $\mathrm{CO}_{2}$ concentration field at $250 \mathrm{hPa}$ for June 2007, as simulated by NICAM-TM, and the locations of the CONTRAll measurements for 2007 (white dots). (b) Monthly variation of the $\mathrm{CO}_{2}$ flux averaged for 2006 to 2008, estimated by the inversion analysis of Niwa et al. (2012) (this figure is slightly modified from Figure 5d in Niwa et al. 2012). The blue and red lines are the $\mathrm{CO}_{2}$ fluxes (positive values indicate sources and negative values indicate sinks) estimated by only using surface data and by using both surface and CONTRAIL data, respectively, and the colored shades and error bars denote the range of the estimated flux uncertainty and standard deviation for 2006 to 2008, respectively.

such as within regions with finer mesh sizes, resolutiondependent parameters are not required. The stretch NICAM is widely used for studies on tropical convective systems (Satoh et al. 2010; Satoh and Kitao 2013; Roh and Satoh 2014), tropical cyclones (Yanase et al. 2010a, b; Satoh et al. 2013; Arakane et al. 2014), and MJOs (Nasuno 2013).

The other approach is similar to the use of a regional model. Only 1 of the 10 diamond regions that make up the icosahedral grid is used for the simulation (hereinafter, the diamond NICAM). The simulation domain of the diamond NICAM consists of 1 diamond (2 triangles of an icosahedron), even though the original NICAM global domain consists of 10 diamonds (20 triangles). The diamond NICAM is used as a non-hydrostatic regional model. By using this approach, we can share the same code for both the global domain and limited-area models. This is advantageous for the maintenance of the source code because all components of NICAM are used in common in both models.

To enable the limited-area simulations using the diamond NICAM, we developed a nudging scheme in which the strength of the nudge depends on the distance from a certain point on the globe. Figure 11 shows the simulation domain of a regional climate simulation targeted on Japan. The lateral boundary of the simulation domain (outer edge of the gray circle in Figure 11) is forced by six-hourly reanalysis data. Verification of the diamond NICAM is still under investigation and the results of test simulations performed using the diamond NICAM were compared with the results of the high-resolution experiments using the stretch and global NICAM. The comparison results showed good agreement with those produced by the original global NICAM simulation. The temporal evolution of a convective system, such as the locations of triggering, development, and decay, was also well simulated during the integration.

\section{Plane NICAM}

Although the stretch and diamond NICAM can be used for limited-area simulations, an $f$-plane system is useful when conducting some types of numerical simulations, such as idealized simulations on an $f$-plane and

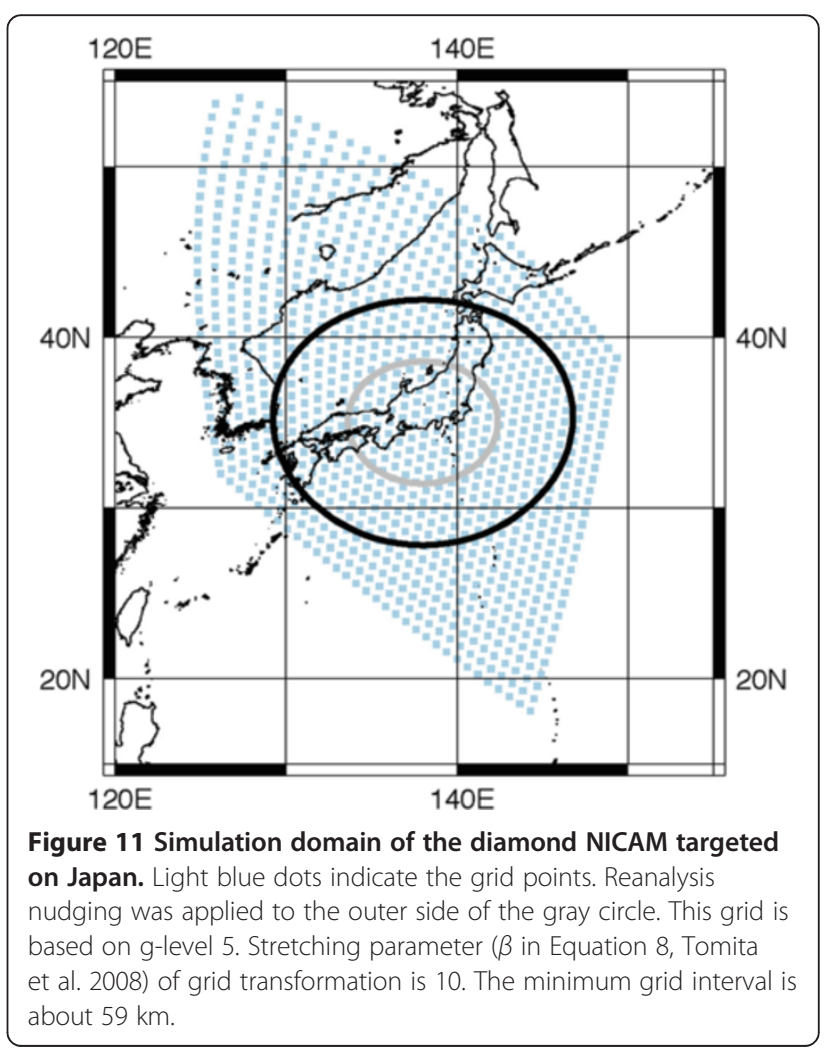


simulations with a narrow region in which the curvature of the Earth is not important. For this reason, an $f$-plane model (hereinafter, the plane NICAM) whose dynamical core is the same as the original NICAM was developed. To save maintenance costs, the plane NICAM used the same code as the global NICAM, which also makes knowledge gained by the plane NICAM immediately and directly applicable to the global NICAM.

In the plane NICAM, the shape of the calculation domain is a diamond composed of two regular triangles with a double periodic lateral boundary condition. Figure 12 shows the configuration of the calculation domain for the plane NICAM, as indicated by black bold lines. The outward fluxes across side $\mathrm{AB}$ are equivalent to the inward fluxes across side DC. The red, green, blue, and yellow areas inside the diamond area surrounded by the black bold lines correspond to the hatched areas of the same respective color. Therefore, if the double periodic boundary condition is applied to the diamond-shaped domain with side length $L$, the calculation domain is equivalent to the regular hexagonal domain with side length $l=L / \sqrt{ } 3$, as represented by the hatched area in Figure 12. Regular hexagonal geometry is better suited than square or regular triangle geometry in terms of isotropy.

As an example of the use of the plane NICAM, we briefly show a result of an idealized tropical cyclone simulation on an $f$-plane (Ohno and Satoh 2014). The model was initialized with an axisymmetric cyclonic vortex that had a maximum azimuthal wind of $12 \mathrm{~m} \mathrm{~s}^{-1}$ as formulated by Rotunno and Emanuel (1987). The initial thermodynamic structure of the unperturbed model atmosphere is defined by moist adiabatic lapse rate up to $17 \mathrm{~km}$ and a constant temperature above this height.

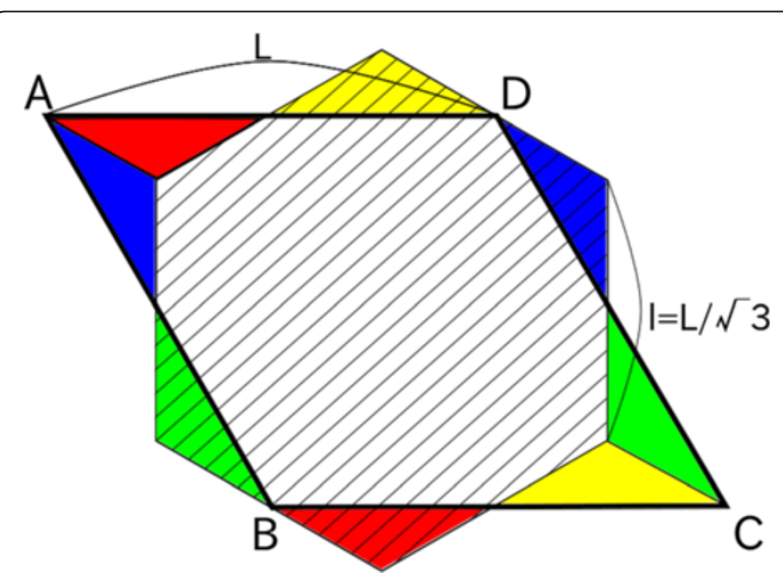

Figure $12 \mathrm{~A}$ schematic image of the calculation domain for the plane NICAM. A schematic image showing the relationship between the calculation domain and a unit cell for the plane NICAM. The diamond-shaped area (ABCD) surrounded by black bold lines indicates the calculation domain, and the hatched regular hexagonal area indicates the unit cell.
The length of the sides of the numerical domain is $L=$ $3,000 \mathrm{~km}$, and a horizontal resolution of $2.7 \mathrm{~km}$ is used for the entire domain. We used 50 vertical levels up to $45 \mathrm{~km}$ where the intervals of the vertical levels become smaller in the boundary layer. The SST is fixed at $31^{\circ} \mathrm{C}$ and an $f$-plane with a constant Coriolis parameter at $18 \mathrm{~N}$ is assumed. After an initial shock, the minimum sea level pressure continued to drop for $140 \mathrm{~h}$ and a quasi-steady stage was achieved. The cyclone reached a minimum central surface pressure of $931 \mathrm{hPa}$ at about $160 \mathrm{~h}$. A plan view of the distribution of the hourly precipitation amounts after $128 \mathrm{~h}$ of the time integration is shown in Figure 13, which indicates that the tropical cyclone has an eye, an eyewall, inner core rainbands, and distant rainbands. The array of rainbands and the eyewall are typical features of a tropical cyclone (Houze 2010).

\section{Further modified grids}

In addition to the original icosahedral grid, alternative spherical grids denoted by extended triangular meshes (XTMS) (Iga 2014a) are also implemented on NICAM. The mesh topologies of these grids are different from the topology of an icosahedral grid and are generated by three processes: grid relaxation via spring dynamics, transformation via an analytical function, and the Schmidt transformation. By changing mesh topologies and transformation functions, it is possible to obtain a grid with non-uniform distributions of resolution on a sphere, which is applicable to various situations. For example, the resolution can be increased at a particular region or along a tropical zone as shown by Figure 14a,b. The grid structure shown by Figure 14a looks similar to that of the stretch NICAM, but the variability of the horizontal mesh spacing is smaller and the variability of the resolution is smoother than that of the stretch NICAM. The resolution is approximately proportional to the combination of map factors of two polar stereographic projections. As for the grid structure shown by Figure 14b, resolution is enhanced along the equatorial belt and is approximately proportional to the combination of map factors of two Lambert conformal conic projections and one Mercator projection (hereinafter, LML grid). The LML grid is more useful for studying the multi-scale structure of convective systems in the tropics. The performance of the LML grid was examined by aqua planet experiments (Iga 2014b).

\section{Coupler}

Currently, high-resolution NICAM is mainly used for short-term simulations such as for tropical cyclones and intra-seasonal variability. Since deep sea circulations are not important for these simulations, a simple mixedlayer ocean model is implemented in NICAM. However, in order to cover wider areas of research, such as 


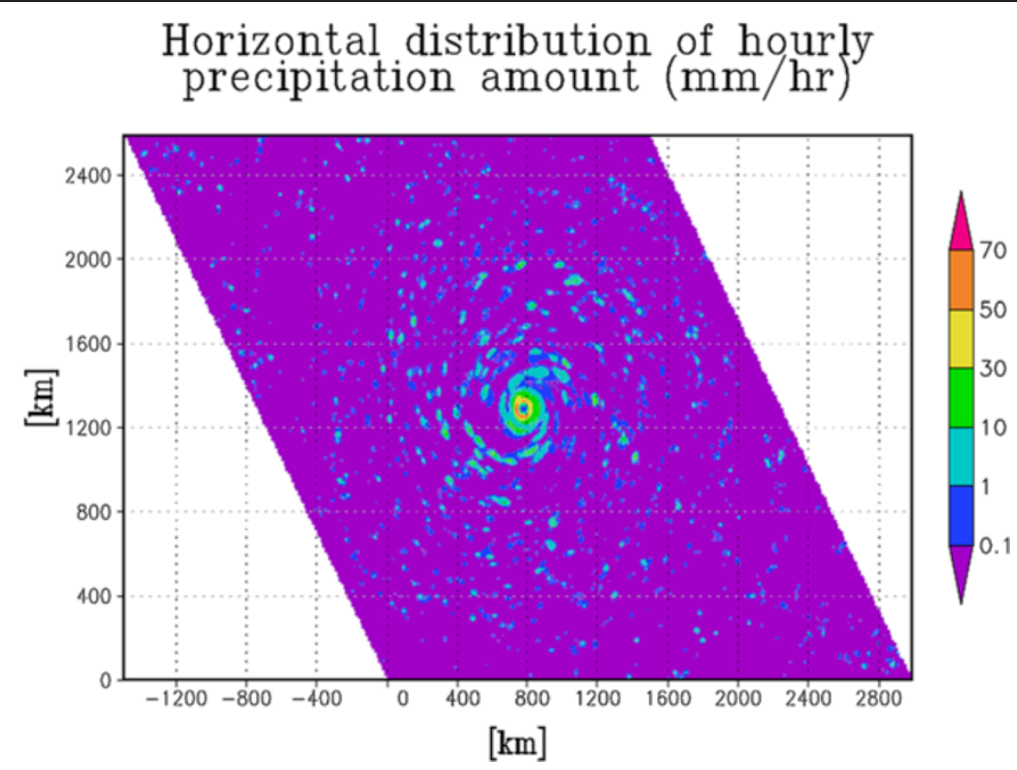

Figure 13 A horizontal distribution of precipitation for a tropical cyclone simulation by the plane NICAM. A horizontal distribution of hourly precipitation amount by the plane NICAM after a time integration of $128 \mathrm{~h}$ for a $2.7 \mathrm{~km}$ mesh tropical cyclone simulation.

climate projection, coupling with an ocean model is necessary when NICAM is used as an atmospheric component of an Earth system model. To couple an atmosphere model and an ocean model, we used a coupler called Jcup (Figure 15). Because Jcup connects models with different grid systems, it can be used as a grid transformation tool. Thus, in addition to ocean coupling, Jcup is used as an I/O tool of NICAM by converting the output data from the icosahedral grid to the lat-lon grid which is generally used for analysis. In this section, the Jcup coupling library that was used as a core of the coupled model system will be introduced first, after which the ocean and $\mathrm{I} / \mathrm{O}$ coupling will be described.

The Jcup coupling library is a collaborative work of JMA/MRI, JAMSTEC, and the Research Organization for Information Science and Technology (RIST) (Arakawa and Yoshimura 2009; Arakawa et al. 2011), that is freely available as an open source program at https:// sites.google.com/a/rist.jp/jcup/. Jcup inherited the development experience and design concept of Scup, which was developed by Yoshimura and Yukimoto (2008). The most remarkable feature of Jcup is its wide applicability. Generally speaking, the applicability range of a coupler is restricted by the specific grid structures and interpolation schemes it supports. For example, OASIS version 4 supported logically rectangular (i.e., 2D structured) or reduced Gaussian grids, along with bilinear, trilinear, bicubic, nearest-neighbor, and 2D conservative interpolations (Redler et al. 2009). This indicates that the models that utilize other grid systems, such as non-structured or substructured grids, cannot be coupled.

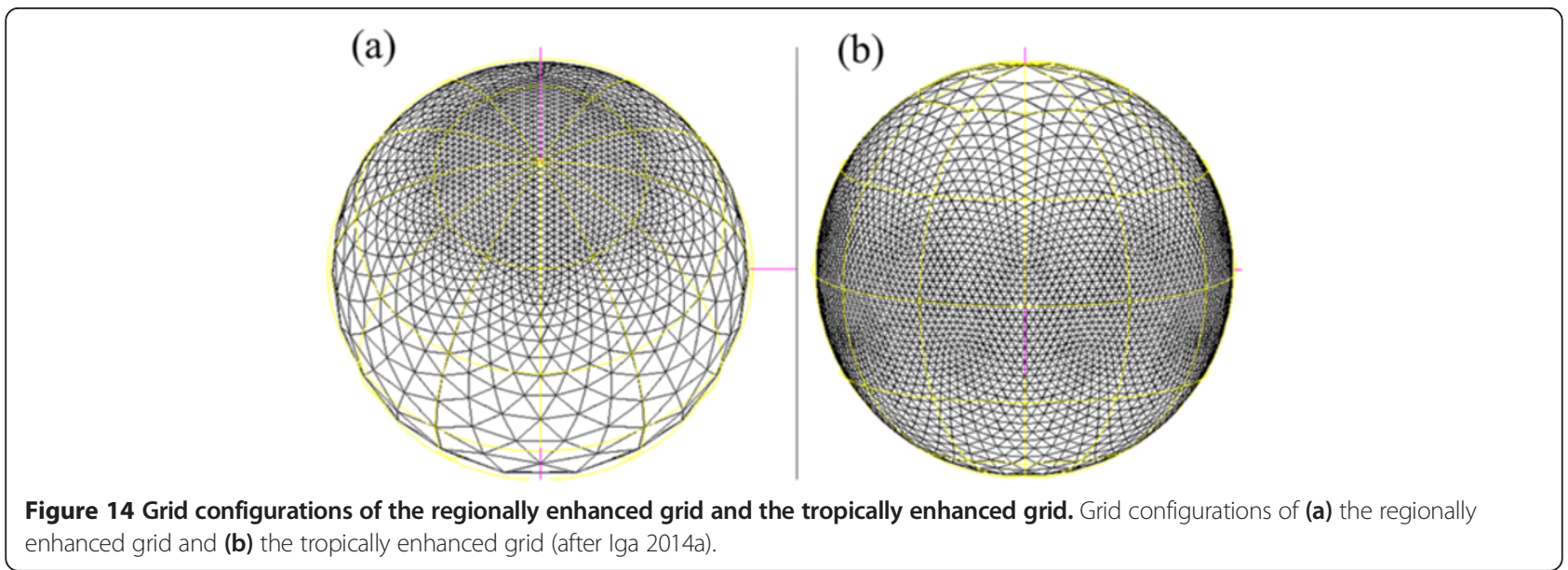




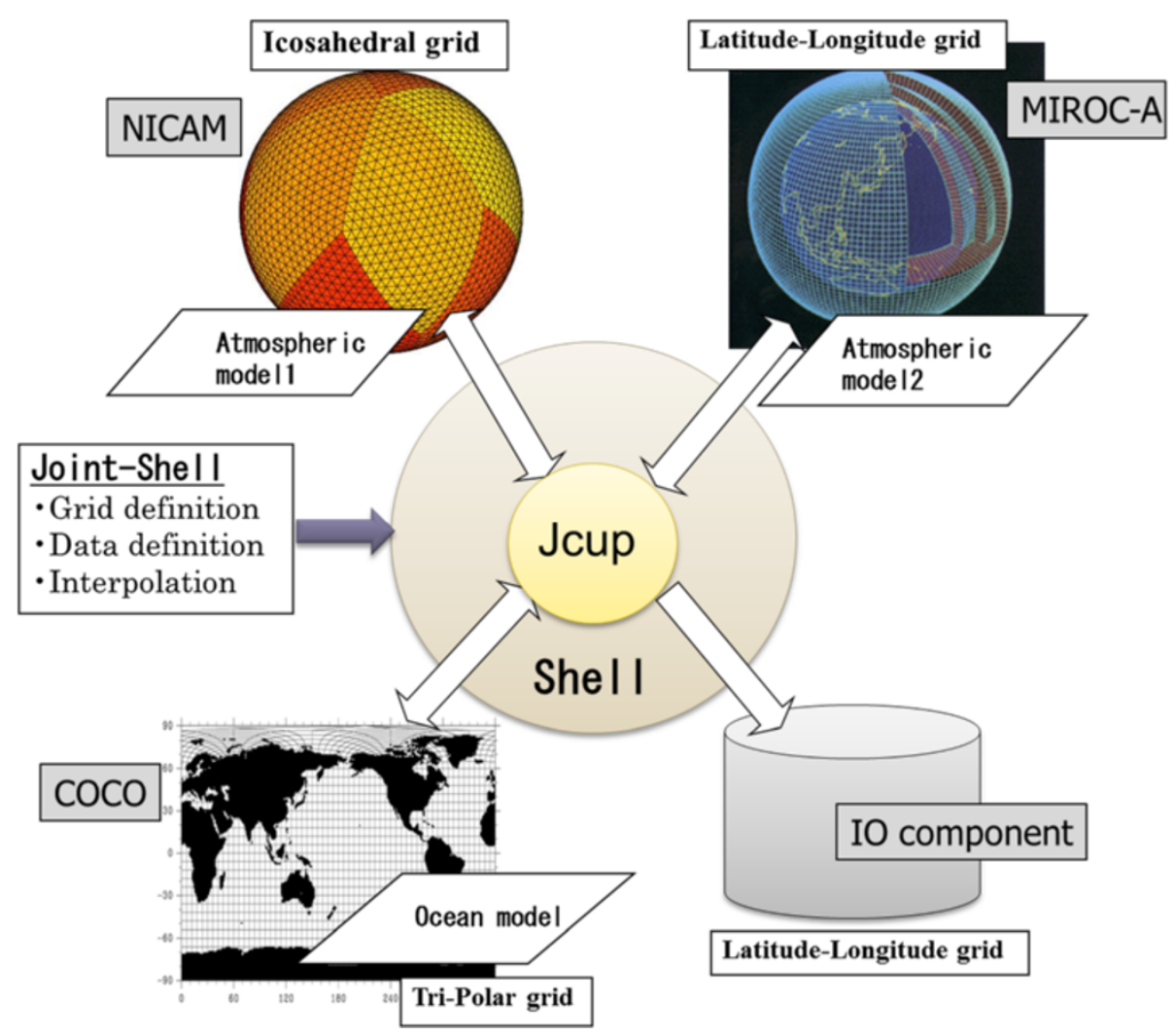

Figure 15 A schematic of the coupling system.

The spectral method has been widely used for global atmospheric models. However, this method is not suitable for massively parallel processor (MPP) supercomputers because all-to-all communication is required. This is one reason why substructured grid models such as NICAM were developed energetically by the research organizations of numerous countries. Therefore, it is also necessary to develop a coupler that can handle such models. Jcup is specifically designed to couple different grid systems, so users can (and must) implement their own interpolation code and prepare a 'mapping table' in advance. See Arakawa et al. (2011) for details.

Next, we will describe NICAM and ocean model coupling. Currently, the Center for Climate System Research (CCSR) Ocean Component Model (COCO) (Hasumi 2000, 2006) is used for the ocean model coupled with NICAM. In the coupler of the NICAM-COCO coupled model, Jcup is used as a core library and is implemented via a package called Joint-shell, which contains definition of the grid structures, exchange data, and the interpolation code (Figure 15). The interpolation code is based on the first-order conservative remapping scheme in Jones (1999). The 'mapping table' that must be set up as external files for beforehand defines grid-to-grid relations and Jcup's weight for grid systems of coupled models.
Furthermore, we also implement a utility program to calculate such table files as a part of the Joint-shell. Note that COCO adopts a tri-polar grid, in which the northern polar region grid points do not follow latitude-longitude lines. As a result, coupling NICAM and COCO requires coupling two substructured grid models, which is why Jcup is used as a core of the coupler.

To couple NICAM, a new module has been implemented to replace the mixed-layer ocean module that has already implemented. Most of the other parts, such as the dynamical core, cloud microphysics, and land models, are untouched. The physical quantities exchanged between NICAM and COCO are listed in Table 3. The most significant issue was the inconsistency of ocean definition points between the two models. More specifically, some points that are recognized as ocean points by NICAM are recognized as land points by COCO. At such grid points, no data are provided to NICAM. Inconsistencies such as this occur if the land-ocean distribution has been set independently between the two models. In the future, we plan to improve pre-process utilities in order to create a NICAM land-ocean map that will maintain consistency with the $\mathrm{COCO}$ map. However, to avoid this problem in the interim, we applied the mixed-layer ocean module, which is pre-implemented in NICAM to such grid points. 


Table 3 Physical quantities exchanged between NICAM
and COCO through the coupler
\begin{tabular}{lc}
\hline NICAM to COCO & COCO to NICAM \\
\hline Wind stress to ocean (eastward) & Sea surface temperature \\
Wind stress to ocean (northward) & Sea ice thickness \\
Wind stress to sea ice (eastward) & Ice covered ratio \\
Wind stress to sea ice (northward) & Snow amount on sea ice \\
Energy flux from atmosphere to ocean & Temperature of sea ice \\
Energy flux from atmosphere to sea ice & \\
Energy flux from sea ice to ocean & \\
Radiation flux (short wave) & \\
Sublimation from sea ice & \\
Evaporation & \\
Precipitation & \\
Snowfall & \\
Runoff
\end{tabular}

The icosahedral grid employed by NICAM cannot be used to analyze the results. For example, the calculation of the zonal mean values is not straightforward and the visualization tools assume a lat-lon grid in many cases. Because of this, we generally use a conversion tool called 'ico2ll' to move data from the icosahedral grid to the lat-lon grid for post-processing of simulations. However, in many cases, running ico2ll as a post-process results in a bottle neck because it requires numerous $\mathrm{I} / \mathrm{O}$ transfers and cannot parallelize itself since it is necessary to create a single file for the lat-lon grid of each variable. Jcup allows NICAM-I/O coupling, which leads to an efficient I/O conversion, to be successfully achieved. More specifically, the I/O module converts the icosahedral grid to the lat-lon grid and is executed in parallel with NICAM. The implemented conversion schemes include a bi-linear interpolation, a control volume weighted average, and the nearest-neighbor method. A bi-linear interpolation is originally implemented method in the stand-alone version of ico2ll', and this method has first-order accuracy. The control volume weighted average scheme is the same with the one used in NICAM-COCO coupling and also has first-order accuracy, but the global averaged fluxes are conserved. The nearest-neighbor method has less accuracy and conservation properties than the other two methods. This method was implemented due to the demands from NICAM users and is used to provide a quick look at the raw values by using the general latitude-longitude graphic tools, such as the Grid Analysis and Display System (GrADS), without an averaging process. These schemes can be set for each output data type and can be switched by altering the configuration file.

Figure 15 is a schematic of the coupling system described above. The coupling system is designed so that NICAM automatically detects the coupling pattern at runtime without taking any other configuration. For example, when $\mathrm{COCO}$ is executed in parallel with NICAM, subroutines for NICAM-COCO coupling are used, and if not, subroutines of the mixed-layer ocean model are called. I/O is also the same as the case of COCO, in which NICAM automatically sends output data to $\mathrm{I} / \mathrm{O}$ only when the $\mathrm{I} / \mathrm{O}$ component is executed.

\section{Conclusions}

This paper reviewed recent activities of the global nonhydrostatic model, NICAM, and described its development and the details of each component of the dynamics and physics, the strategy of assimilation, and the related models. In the 'Introduction' section, a review of other global nonhydrostatic models, scientific overviews of NICAM, and the current design/structure and a future timeframe of NICAM were described. In the 'Dynamics' section, horizontal grid issues and vertical resolution issues were discussed. In the 'Physics' section, components of cloud microphysics, subgrid-scale turbulence, radiation, aerosol and chemistry, and land surface were described. As for assimilation, NICAM-LETKF was presented, and NICAMTM was introduced to describe the assimilation of the transport model. The 'Models related to NICAM' section showed a variety of ways that NICAM can be used, specifically, stretch NICAM, diamond NICAM, plane NICAM, the tropically enhanced grid model, and coupling with the ocean model or the I/O module.

A number of comprehensive NICAM-related review articles have been published (Satoh et al. 2008; Satoh 2013) since the $3.5 \mathrm{~km}$ mesh global non-hydrostatic experiments were conducted by Tomita et al. (2005) and Miura et al. (2007b). However, these were primarily limited to descriptions of the governing equations, and because many of the model components continue to evolve and develop as the entire package expands, we were requested to provide a comprehensive overview of NICAM activities and future projections. NICAM has been a pioneering global nonhydrostatic model for almost a decade, and now that other global non-hydrostatic models are emerging, we believe that our experiences and considerations will be useful for other high-resolution modeling groups. Mutually beneficial information exchanges between different modeling groups will be required for future fruitful studies during the forthcoming era of global non-hydrostatic modeling.

\section{Abbreviations}

AICS: RIKEN Advanced Institute for Computational Science;

AORI: Atmosphere and Ocean Research Institute, The University of Tokyo; AGCM: atmospheric general circulation model; AMIP: Atmospheric Model Intercomparison Project; CALIPSO: Cloud-Aerosol Lidar and Infrared Pathfinder Satellite Observations; CCSR: Center for Climate System Research, The University of Tokyo; CFL condition: Courant-Friedrichs-Lewy condition; CFMIP: Cloud Feedback Model Intercomparison Project; CHASER: Chemical Atmospheric General Circulation Model for Study of 
Atmospheric Environment and Radiative Forcing; CINDY2011: Cooperative Indian Ocean Experiment on Intraseasonal Variability in the Year 2011; CONTRAIL: Comprehensive Observation Network for Trace Gases by Airliner Project; COCO: CCSR Ocean Component Model; COSP: CFMIP Observation Simulator Package; CWC: consistency with continuity; DYNAMO: Dynamics of the MJO; EnKF: ensemble Kalman filter; ETKF: ensemble transform Kalman filter; ES: Earth Simulator; ES2: Earth Simulator 2; GrADS: Grid Analysis and Display System; GOSAT: Greenhouse Gases Observing Satellite; g-level: grid division level; ISCCP: International Satellite Cloud Climatology Project; JAMSTEC: Japan Agency for Marine-Earth Science and Technology; JCDAS: JMA Climate Data Assimilation System; JMA: Japan Meteorological Agency; J-simulator: Joint Simulator for Satellite Sensors; LETKF: local ensemble transform Kalman filter; MATSIRO: Minimal Advanced Treatments of Surface Interaction and Runoff; MEXT/RECCA/SALSA: Development of Seamless Chemical Assimilation System and its Application for Atmospheric Environmental Material (SALSA) Project of the Research Program on Climate Change Adaptation (RECCA) in Ministry of Education, Culture, Sports, Science and Technology, Japan (MEXT); MIROC: Model for Interdisciplinary Research on Climate; MIROC ESM: MIROC Earth System Model; MISMO: Mirai Indian Ocean cruise for the study of the MJO-convection onset; MRI: Meteorological Research Institute; MSTRN-X: the latest version of the broadband radiative transfer model MSTRN based on the discrete ordinate method with a delta two-stream approximation; MTSAT-1R: Multi-functional Transport Satellite; MYNN: Mellor-Yamada Nakanishi-Niino scheme; MY: Mellor-Yamada Scheme; NDW6: NICAM Double Moment Scheme with six water categories; NSW6: NICAM Single Moment Scheme with six water categories; NICAM: non-hydrostatic icosahedral atmospheric model; NICAM-Chem: Unified Aerosol-Chemistry Model coupled to NICAM; NIES: National Institute for Environmental Studies; RIST: Research Organization for Information Science and Technology; SPRINTARS: Spectral Radiation-Transport Model for Aerosol Species; SWM: Shallow Water Model; TRMM: Tropical Rainfall Measuring Mission; VOC: volatile organic compound; XTMS: extended triangular meshes.

\section{Competing interests}

The authors declare that they have no competing interests. For more information, visit the website, 'http://nicam.jp/.'

\section{Authors' contributions}

MS and HT coordinated the structure of the paper and wrote the 'Introduction' and 'Conclusions' sections. HY wrote the 'Design, structure, development, and timeline' and 'Radiation' sections. In the 'Dynamics' section, HM wrote the 'Grid configuration and advection scheme' section, while CK and MS wrote the Vertical resolution issues' section. In the 'Physics' section, TS wrote the 'Cloud microphysics schemes' section, while AN wrote the 'Subgrid-scale turbulence of the planetary boundary layer' section using experimental data simulated by YY. DG wrote the 'Aerosol and chemistry modules' section, and MH wrote the 'Land model' section. In the 'Assimilation' section, MSw and TM wrote the 'Local ensemble transform Kalman filter applied to NICAM: NICAM-LETKF' section, while YN wrote the 'NICAM-based transport model: NICAM-TM' section. In the 'Models related to NICAM' section, MH wrote the 'Stretch NICAM and diamond NICAM' section, while TO wrote the 'Plane NICAM' section. The 'Further modified grids' section was written by $\mathrm{SI}$, and the 'Coupler' section was written by TA, TI, and HK. All authors read and approved the final manuscript.

\section{Acknowledgements}

This research used the computational resources of the High Performance Computing Infrastructure ( $\mathrm{HPCl}$ ) system provided by the Information Technology Center of The University of Tokyo, through the HPCI System Research Project (Project ID:hp120190). The K computer at AICS was used under the supported by Strategic Programs for Innovative Research (SPIRE) Field 3 (Projection of Planet Earth Variations for Mitigating Natural Disasters), which is funded by MEXT (ID: hp120279 and hp130010). Earth Simulator at JAMSTEC and FX10 at The University of Tokyo were also used. The development of coupler is supported by Japan Science and Technology Agency/Core Research for Evolutional Science and Technology (JST/CREST), 'ppOpen-HPC: Open Source Infrastructure for Development and Execution of Large-Scale Scientific Applications on Post-Peta-Scale Supercomputers with Automatic Tuning (AT)'. The development of the diamond NICAM and NICAM-Chem is supported by MEXT/RECCA/SALSA.

\section{Author details}

'Atmosphere and Ocean Research Institute, The University of Tokyo, 5-1-5 Kashiwanoha, Kashiwa, Chiba 277-85648, Japan. ${ }^{2} J a p a n$ Agency for Marine-Earth Science and Technology, 3173-15, Showa-machi, Kanazawa-ku, Yokohama, Kanagawa 236-0001, Japan. ${ }^{3}$ RIKEN Advanced Institute for Computational Science, 7-1-26, Minatojima-minami-machi, Chuo-ku, Kobe, Hyogo 650-0047, Japan. ${ }^{4}$ Department of Earth and Planetary Science, The University of Tokyo, 7-3-1 Hongo, Bunkyo-ku, Tokyo 113-0033, Japan.

${ }^{5}$ National Institute for Environmental Studies, 16-2 Onogawa, Tsukuba, Ibaraki 305-8568, Japan. ${ }^{6}$ Meteorological Research Institute, 1-1 Nagamine, Tsukuba, Ibaraki 305-0052, Japan. ${ }^{7}$ Research Organization for Information Science and Technology, 2-32-3, Kitashinagawa, Shinagawa-ku, Tokyo 140-0001, Japan.

\section{Received: 13 March 2014 Accepted: 21 August 2014}

\section{Published online: 14 October 2014}

\section{References}

Adcroft A, Hill C, Marshall J (1997) Representation of topography by shaved cells in a height coordinate ocean model. Mon Wea Rev 125:2293-2315

Albrecht BA (1989) Aerosols, cloud microphysics, and fractional cloudiness. Science 245:1227-1230

Arakane T, Satoh M, Yanase W (2014) The excitation of the deep convection to the north of tropical storm Bebinca (2006). J Meteor Soc Japan 92:141-161

Arakawa A (2004) The cumulus parameterization problem: past, present, and future. J Clim 17:2493-2525

Arakawa A, Lamb VR (1977) Computational design of the basic dynamical processes of the UCLA general circulation model. Methods Comput Phys 17:173-265

Arakawa T, Yoshimura H (2009) Performance evaluation of a coupling software for climate modeling (in Japanese). J Inform Process Japan 2:95-110

Arakawa T, Yoshimra H, Saito F, Ogochi K (2011) Data exchange algorithm and software design of KAKUSHIN coupler Jcup. Procedia Comp Sci 4:1516-1525

Berger AL (1978) Long-term variations of daily insolation and quaternary climatic changes. J Atmos Sci 35:2362-2367

Berry EX, Reinhardt RL (1974) An analysis of cloud drop growth by collection: part II. Single initial distribution. J Atmos Sci 31:1825-1831

Bishop CH, Etherton B, Majumdar SJ (2001) Adaptive sampling with the ensemble transform Kalman filter. Part I: theoretical aspects. Mon Wea Rev 129:420-436

Blackburn M, Williamson DL, Nakajima K, Ohfuchi W, Takahashi YO, Hayashi Y-Y, Nakamura H, Ishiwatari M, McGregor J, Borth H, Wirth V, Frank H, Bechtold P, Wedi NP, Tomita H, Satoh M, Zhao M, Held IM, Suarez MJ, Lee M-I, Watanabe M, Kimoto M, Liu Y, Wang Z, Molod A, Rajendran K, Kitoh A, Stratton R (2013) The Aqua-Planet Experiment (APE): Control SST simulation. J Meteor Soc Japan 91A:17-56

Bodas-Salcedo A, Webb MJ, Bony S, Chepfer H, Dufresne JL, Klein SA, Marchand R, Haynes JN, Pincus R, John VO (2011) COSP: satellite simulation software for model assessment. Bull Am Meteorol Soc 91:1023-1043

Bonaventura L (2000) A semi-implicit semi-Lagrangian scheme using the height coordinate for a nonhydrostatic and fully elastic model of atmospheric flows. J Comp Phys 158:186-213

Bryan GH, Wyngaard JC, Fritsch JM (2003) Resolution requirements for the simulation of deep moist convection. Mon Wea Rev 131:2394-2416

Cheong H-B (2006) A dynamical core with double Fourier series: comparison with the spherical harmonics method. Mon Wea Rev 134:1299-1315

Collins WD, Satoh M (2009) Simulating global clouds, past, present, and future. In: Heintzenberg J, Charlson RJ (eds) Clouds in the perturbed climate system: their relationship to energy balance, atmospheric dynamics, and precipitation, Struengmann Forum Report, vol. 2. The MIT Press, Cambridge, pp 469-486

Côté J, Gravel S, Méthot A, Patoine A (1998) The operational CMC-MRB global environmental multiscale (GEM) model. Part l: design considerations and formulation. Mon Wea Rev 126:1373-1395

Cullen MJP, Davies T, Mawson MH, James JA, Coutler SC, Malcolm A (1997) An Overview of Numerical Methods for the Next Generation U. K. NWP and Climate Model. In: Lin CA et al (eds) Numerical Methods in Atmospheric and Oceanic Modelling. The Andrew J. Robert Memorial Volume, NRC Research Press, Ottawa, pp 425-444

Dai T, Goto D, Schutgens NAJ, Dong X, Shi G, Nakajima T (2014a) Simulated aerosol key optical properties over global scale using an aerosol transport coupled with a new type of dynamic core. Atmos Environ 82:71-82 
Dai T, Schutgens NAJ, Goto D, Shi G, Nakajima T (2014b) Improvement of aerosol optical properties modeling over Eastern Asia with MODIS AOD assimilation in a global non-hydrostatic icosahedral aerosol transport model. Environ Pollut doi:10.1016/j.envpol.2014.06.021

Davies T, Cullen MJP, Malcolm AJ, Mawson MH, Staniforth A, White AA, Wood N (2005) A new dynamical core for the Met Office's global and regional modelling of the atmosphere. Quart J Roy Meteor Soc 131:1759-1782

Dirmeyer PA, Cash BA, Kinter JL III, Jung T, Marx L, Satoh M, Stan C, Tomita H, Towers P, Wedi N, Achuthavarier D, Adams JM, Altshuler EL, Huang B, Jin EK, Manganello J (2012) Simulating the diurnal cycle of rainfall in global climate models: resolution versus parameterization. Clim Dyn 39:399-418

Emanuel K, Oouchi K, Satoh M, Tomita H, Yamada Y (2010) Comparison of explicitly simulated and downscaled tropical cyclone activity in a high-resolution global climate model. J Adv Model Earth Syst 2:9, doi:10.3894/JAMES.2010.2.9

Enting IG (2002) Inverse problems in atmospheric constituent transport. Cambridge University Press, Cambridge, p 392, doi:10.1017/ CBO9780511535741

Evensen G (1994) Sequential data assimilation with a nonlinear quasi-geostrophic model using Monte-Carlo methods to forecast error statistics. J Geophys Res 99:10143-10162

Feingold G, Walko RL, Stevens B, Cotton WR (1998) Simulations of marine stratocumulus using a new microphysical parameterization scheme. Atmos Res 47-48:505-528

Fu X, Wang B (2004) Differences of boreal summer intraseasonal oscillations simulated in an atmosphere-ocean coupled model and an atmosphere-only model. J Clim 17:1263-1271

Fudeyasu H, Wang Y, Satoh M, Nasuno T, Miura H, Yanase W (2008) The global cloud-system-resolving model NICAM successfully simulated the lifecycles of two real tropical cyclones. Geophys Res Lett 35:L22808, doi:10.1029/ 2008GL0360033

Fudeyasu H, Wang Y, Satoh M, Nasuno T, Miura H, Yanase W (2010a) Multiscale interactions in the lifecycle of a tropical cyclone simulated in a global cloud-system-resolving model. Part I: large scale aspects. Mon Wea Rev 138:4285-4304

Fudeyasu H, Wang Y, Satoh M, Nasuno T, Miura H, Yanase W (2010b) Multiscale interactions in the lifecycle of a tropical cyclone simulated in a global cloudsystem-resolving model. Part II: mesoscale and storm-scale processes. Mon Wea Rev 137:3254-3268

Fujita M, Yoneyama K, Mori S, Nasuno T, Satoh M (2011) Diurnal convection peaks over the eastern Indian Ocean off Sumatra during different MJO phases. J Meteor Soc Japan 89A:317-330

Gal-Chen T, Somerville CJ (1975) On the use of a coordinate transformation for the solution of the Navier-Stokes equations. J Comp Phys 17:209-228

Gallus WA Jr, Klemp JB (2000) Behaviour of flow over step orography. Mon Wea Rev 128:1153-1164

Goto D (2014) Modeling of black carbon in Asia using a global-to-regional seamless aerosol-transport model. Environ Pollut doi:10.1016/j.envpol.2014.06.006

Goto D, Nakajima T, Takemura T, Sudo K (2011a) A study of uncertainties in the sulfate distribution and its radiative forcing associated with sulfur chemistry in a global aerosol model. Atmos Chem Phys 11:10889-10910

Goto D, Takemura T, Nakajima T, Badarinath KVS (2011b) Global aerosol model-derived black carbon concentration and single scattering albedo over Indian region and its comparison with ground observations. Atmos Environ 45:3277-3285

Goto D, Kanazawa S, Nakajima T, Takemura T (2012) Evaluation of a relationship between aerosols and surface downward shortwave flux through an integrative analysis of modeling and observation. Atmos Environ 49:294-301

Goto D, Dai T, Satoh M, Tomita H, Uchida J, Misawa S, Inoue T, Tsuruta H, Ueda K, Ng CFS, Takami A, Sugimoto N, Shimizu A, Ohara T, Nakajima T (2014) Application of a global nonhydrostatic model with a stretched-grid system to regional aerosol simulations around Japan. Geosci Model Dev Discuss 7:131-179

Grabowski WW (1998) Toward cloud resolving modeling of large-scale tropical circulations: a simple cloud microphysics parameterization. J Atmos Sci 55:3283-3298

Gross ES, Bonaventura L, Rosatti G (2002) Consistency with continuity in conservative advection schemes for free-surface models. Int J Numer Meth Fluids 38:307-327

Gurney KR, Law RM, Denning AS, Rayner PJ, Baker D, Bousquet P, Bruhwiler L, Chen YH, Ciais P, Fan S, Fung IY, Gloor M, Heimann M, Higuchi K, John J, Maki T, Maksyutov S, Masarie L, Peylin P, Prather M, Pak BC, Randerson J,
Sarmiento J, Taguchi S, Takahashi T, Yuen CW (2002) Towards robust estimates of $\mathrm{CO}_{2}$ sources and sinks using atmospheric transport models. Nature 415:626-630

Ham S-H, Sohn B-J, Kato S, Satoh M (2013) Vertical inhomogeneity of ice cloud layers from CloudSat and CALIPSO measurements and comparison to NICAM simulations. J Geophys Res 118:9930-9947

Hansen JE, Travis LD (1974) Light scattering in planetary atmosphere. Space Sci Rev 16:527-610

Hashino T, Satoh M, Hagihara Y, Kubota T, Matsui T, Nasuno T, Okamoto H (2013) Evaluating global cloud distribution and microphysics from the NICAM against CloudSat and CALIPSO. J Geophys Res 118:7273-7292

Hasumi H (2000) CCSR Ocean Component Model (COCO). CCSR Rep 13. The University of Tokyo, Chiba, Japan

Hasumi H (2006) CCSR Ocean Component Model (COCO) version 4.0. CCSR Rep 25. The University of Tokyo, Chiba, Japan

Hasumi H, Emori S (2004) K-1 coupled model (MIROC) description. K-1 Tech Rep. p 34, http://ccsr.aori.u-tokyo.ac.jp/ hasumi/miroc_description.pdf. Accessed at 29 Sep 2014

Hayashi YY, Sumi A (1986) The 30-40 day oscillations simulated in an aqua-planet model. J Meteorol Soc Japan 64:451-467

Heikes R, Randall DA (1995) Numerical integration of the shallow-water equations on a twisted icosahedral grid. Part I: basic design and results of tests. Mon Wea Rev 123:1862-1880

Heikes R, Randall DA, Konor CS (2013) Optimized icosahedral grids: performance of finite-difference operators and multigrid solver. Mon Wea Rev 141:445-4469

Henze DK, Seinfeld JH (2006) Global secondary organic aerosol from isoprene oxidation. Geophys Res Lett 33:L09812, doi:10.1029/2006GL025976

Holloway CE, Woolnough SJ, Lister GMS (2013) The effects of explicit versus parameterized convection on the MJO in a large-domain high-resolution tropical case study. Part l: characterization of large-scale organization and propagation. J Atmos Sci 70:1342-1369

Hong SY, Dudhia J, Chen SH (2004) A revised approach to ice microphysical processes for the bulk parameterization of clouds and precipitation. Mon Wea Rev 132:103-120

Houze RA (2010) Clouds in tropical cyclones. Mon Wea Rev 138:293-344

Hunt BR, Kostelich EJ, Szunyogh I (2007) Efficient data assimilation for spatiotemporal chaos: a local ensemble transform Kalman filter. Physica D 230:112-126

Iga S (2014a) Smooth, seamless and structured grid generation with flexibility in resolution distribution on a sphere based on conformal mapping and spring dynamics method. J Compt Phys submitted

Iga S (2014b) Aqua-planet experiment on an AGCM with tropics-enhanced grid. SOLA, submitted

Iga S, Tomita H (2014) Improved smoothness and homogeneity of icosahedral grids using the spring dynamics method. J Comp Phys 258:208-226

Iga S, Tomita H, Tsushima Y, Satoh M (2007a) Climatology of a nonhydrostatic global model with explicit cloud processes. Geophys Res Lett 34:L22814, doi:10.1029/2007GL031048

Iga S, Tomita H, Satoh M, Goto K (2007b) Mountain-wave-like spurious waves due to inconsistency of horizontal and vertical resolution associated with cold fronts. Mon Wea Rev 135:2629-2641

Iga S, Tomita H, Tsushima Y, Satoh M (2011) Sensitivity of upper tropospheric ice clouds and their impacts on the Hadley circulation using a global cloud-system resolving model. J Climate 24:2666-2679

Inoue T, Satoh M, Miura H, Mapes B (2008) Characteristics of cloud size of deep convection simulated by a global cloud resolving model. J Meteor Soc Japan 86A:1-15

Inoue T, Satoh M, Hagihara Y, Miura H, Schmetz J (2010) Comparison of high-level clouds represented in a global cloud system-resolving model with CALIPSO/ CloudSat and geostationary satellite observations. J Geophys Res 115:D00H22, doi:10.1029/2009JD012371

Iwasaki T, Yamada S, Tada K (1989) A parameterization scheme of orographic gravity wave drag with two different vertical partitionings. Part I: impacts on medium-range forecasts. J Meteor Soc Japan 67:11-27

Jöckel P, von Kuhlmann R, Lawrence M, Steil B, Brenninkmeijer C, Crutzen P, Rasch P, Eaton $B$ (2001) On a fundamental problem in implementing flux-form advection schemes for tracer transport in 3-dimensional general circulation and chemistry transport models. Quart J Roy Meteor Soc 127:1035-1052

Jones PW (1999) First- and second-order conservative remapping schemes for grids in spherical coordinates. Mon Wea Rev 127:2204-2210 
Jung T, Miller MJ, Palmer TN, Towers P, Wedi N, Achuthavarier D, Adams JM, Altshuler EL, Cash BA, Kinter JL III (2012) High-resolution global climate simulations with the ECMWF model in Project Athena: experimental design, model climate, and seasonal forecast skill. J Climate 25:3155-3172

Kalman RE (1960) A new approach to linear filtering and prediction problems. J Basic Eng Trans ASME 82:35-45

Kato S, Rose FG, SunMack S, Miller WF, Chen Y, Rutan DA, Stephens GL, Loeb NG, Minnis P, Wielicki BA, Winker DA, Charlock TP, Stackhouse PW Jr, Xu KM, Collins WD (2011) Improvements of top-of-atmosphere and surface irradiance computations with CALIPSO-, CloudSat-, and MODIS-derived cloud and aerosol properties. J Geophys Res 116:D19209, doi:10.1029/2011JD016050

Kessler E (1969) On the distribution and continuity of water substance in atmospheric circulations. Meteorologial Monograph. Amer Meteor Soc 32:1-84

Khain A, Ovtchinnikov M, Pinsky M, Pokrovsky A, Krugliak H (2000) Notes on the state-of-the-art numerical modeling of cloud microphysics. Atmos Res 55:159-224

Khain A, BenMoshe N, Pokrovsky A (2008) Factors determining the impact of aerosols on surface precipitation from clouds: an attempt at classification. J Atmos Sci 65:1721-1748

Khairoutdinov M, Kogan Y (2000) A new cloud physics parameterization in a large-eddy simulation model of marine stratocumulus. Mon Wea Rev 128:229-243

Khairoutdinov M, Krueger SK, Moeng CH, Bogenschutz PA, Randall DA (2009) Large-eddy simulation of maritime deep tropical convection. J Adv Model Earth Systems 1:15, doi:10.3894/JAMES.2009.1.15

Kikuchi K, Wang B (2010) Formation of tropical cyclones in the northern Indian Ocean associated with two types of tropical intraseasonal oscillation modes. J Meteor Soc Japan 88:475-496

Kinne S, Schulz M, Textor C, Guibert S, Balkanski Y, Bauer SE, Berntsen T, Berglen TF, Boucher O, Chin M, Collins W, Dentener F, Diehl T, Easter R, Feichter J, Fillmore D, Ghan S, Ginoux P, Gong S, Grini A, Hendricks J, Herzog M, Horowitz L, Isaksen I, Iversen T, Kirkevag A, Kloster S, Koch D, Kristjansson JE, Krol M et al (2006) An AeroCom initial assessment - optical properties in aerosol component modules of global models. Atmos Chem Phys 6:1815-1834

Kinter JL III, Cash B, Achuthavarier D, Adams J, Altshuler E, Dirmeyer P, Doty B, Huang B, Marx L, Manganello J, Stan C, Wakefield T, Jin E, Palmer T, Hamrud M, Jung T, Miller M, Towers P, Wedi N, Satoh M, Tomita H, Kodama C, Nasuno T, Oouchi K, Yamada Y, Taniguchi H, Andrews P, Baer T, Ezell M, Halloy C et al (2013) Revolutionizing climate modeling - Project Athena: a multi-institutional, international collaboration. Bull Am Meteor Soc 94:231-245

Klein SA, Jakob C (1999) Validation and sensitivities of frontal clouds simulated by the ECMWF model. Mon Wea Rev 127:2514-2531

Klemp JB (2011) A terrain-following coordinate with smoothed coordinate surfaces. Mon Wea Rev 139:2163-2169

Klemp JB, Wilhemson RB (1978) The simulation of three-dimensional convective storm dynamics. J Atmos Sci 35:1070-1096

Kodama C, Noda AT, Satoh M (2012) An assessment of the cloud signals simulated by NICAM using ISCCP, CALIPSO, and CloudSat satellite simulators. J Geophys Res 117:D12210, doi:10.1029/2011JD017317

Kodama C, Iga S, Satoh M (2014a) Impact of the sea surface temperature rise on storm-track clouds in global non-hydrostatic aqua-planet simulations. Geophys Res Lett 41:3545-3552, doi:10.1002/2014GL059972

Kodama C, Terai M, Noda AT, Yamada Y, Satoh M, Seiki T, Iga S, Yashiro H, Tomita $\mathrm{H}$, Minami K (2014b) Scalable rank-mapping algorithm for an icosahedral grid system on the massive parallel computer with a 3-D torus network. Parallel Comput 40:362-373

Kondo J (1993) A new bucket model for predicting water content in the surface model. J Japan Soc Hydrol and Water Resour 6:344-349 (in Japanese with English abstract)

Kondo K, Tanaka HL (2009) Applying the local ensemble transform Kalman filter to the Nonhydrostatic Icosahedral Atmospheric Model (NICAM). SOLA 5:121-124

Kubokawa H, Fujiwara M, Nasuno T, Satoh M (2010) Analysis of the tropical tropopause layer using the Nonhydrostatic Icosahedral Atmospheric Model (NICAM): aqua planet experiments. J Geophys Res 115:D08102, doi:10.1029/ 2009JD012686

Kubokawa H, Fujiwara M, Nasuno T, Miura H, Yamamoto M, Satoh M (2012) Analysis of the tropical tropopause layer using the Nonhydrostatic Icosahedral Atmospheric Model (NICAM): 2. An experiment under the atmospheric conditions of December 2006 to January 2007. J Geophys Res 117:D17114
Lamarque JF, Shindell DT, Josse B, Young PJ, Cionni I, Eyring V, Bergmann D, Cameron-Smith P, Collins WJ, Doherty R, Dalsoren S, Faluvegi G, Folberth G, Ghan SJ, Horowitz LW, Lee YH, MacKenzie IA, Nagashima T, Naik V, Plummer D, Righi M, Rumbold ST, Schulz M, Skeie RB, Stevenson DS, Strode S, Sudo K, Szopa S, Voulgarakis A, Zeng G (2013) The Atmospheric Chemistry and Climate Model Intercomparison Project (ACCMIP): overview and description of models, simulations and climate diagnostics. Geosci Model Dev 6:179-206

Laprise R (2008) Regional climate modelling. J Comp Phys 227:641-3666

Law RM, Peters W, Rödenbeck C, Aulagnier C, Baker I, Bergmann DJ, Bousquet P, Brandt J, Bruhwiler L, Cameron-Smith PJ, Christensen JH, Delage F, Denning AS, Fan S, Geels C, Houweling S, Imasu R, Karstens U, Kawa SR, Kleist J, Krol MC, Lin SJ, Lokupitiya R, Maki T, Maksyutov S, Niwa Y, Onishi R, Parazoo N, Patra PK, Pieterse G et al (2008) TransCom model simulations of hourly atmospheric $\mathrm{CO}_{2}$ : experimental overview and diurnal cycle results for 2002. Global Biogeochem Cycles 22:GB3009, doi:10.1029/2007GB003050

Lien G-Y, Kalnay E, Miyoshi T (2013) Effective assimilation of global precipitation: simulation experiments. Tellus A 65:19915, http://dx.doi.org/10.3402/tellusa. v65i0.19915

Lim K-SS, Hong S-Y (2010) Development of an effective double-moment cloud microphysics scheme with prognostic cloud condensation nuclei (CCN) for weather and climate models. Mon Wea Rev 138:1587-1612

Lin SJ (2004) A "vertically Lagrangian" finite-volume dynamical core for global models. Mon Wea Rev 132:2293-2307

Lin Y-L, Farley RD, Orville HD (1983) Bulk parameterization of the snow field in a cloud model. J Climate Appl Meteor 22:1065-1092

Liu P, Satoh M, Wang B, Fudeyasu H, Nasuno T, Li T, Miura H, Taniguchi H, Masunaga H, Fu X, Annamalai H (2009) A MJO simulated by the NICAM at 14-km and 7-km resolutions. Mon Wea Rev 137:3254-3268

Lohmann U, Feichter J (2005) Global indirect aerosol effects: a review. Atmos Chem Phys 5:715-737

Machida T, Matsueda H, Sawa Y, Nakagawa Y, Hirotani K, Kondo N, Goto K, Nakazawa T, Ishikawa K, Ogawa T (2008) Worldwide measurements of atmospheric $\mathrm{CO}_{2}$ and other trace gas species using commercial airlines. J Atmos Oceanic Technol 25:1744-1754

Madden RA, Julian PR (1971) Description of a 40-50 day oscillation in the tropics. J Atmos Sci 28:702-708

Madden RA, Julian PR (1972) Description of global-scale circulation cells in the tropics with a 40-50 day period. J Atmos Sci 29:1109-1123

Majewski D, Liermann D, Prohl P, Ritter B, Buchhold M, Hanisch T, Paul G, Wergen W (2002) The operational global icosahedral-hexagonal gridpoint model GME: description and high-resolution tests. Mon Wea Rev 130:319-338

Mapes B, Tulich S, Nasuno T, Satoh M (2008) Predictability aspects of global aqua-planet simulations with explicit convection. J Meteor Soc Japan 86A:175-185

Masuda Y, Ohnishi H (1986) An integration scheme of the primitive equation model with an icosahedral-hexagonal grid system and its application to the shallow water equations. Short- and Medium-Range Numerical Weather Prediction, Collection of Papers Presented at the WMO/IUGG NWP Symposium. Japan Meteorological Society, Tokyo, pp 317-326

Masunaga H, Satoh M, Miura H (2008) A joint satellite and global cloud-resolving model analysis of a Madden-Julian Oscillation event: model diagnosis. J Geophys Res 113:D17210, doi:10.1029/2008JD009986

Matsueda H, Machida T, Sawa Y, Nakagawa Y, Hirotani K, Ikeda H, Kondo N, Goto $\mathrm{K}$ (2008) Evaluation of atmospheric $\mathrm{CO}_{2}$ measurements from new flask air sampling of JAL airliner observations. Pap Meteorol Geophys 59:1-17

McGregor JL (1996) Semi-Lagrangian advection on conformal-cubic grids. Mon Wea Rev 124:1311-1322

Mellor GL, Yamada T (1982) Development of a turbulence closure model for geophysical fluid problems. Rev Geophys Space Phys 20:851-875

Meyers MP, Walko RL, Harrington JY, Cotton WR (1997) New RAMS cloud microphysics parameterization. Part II: the two-moment scheme. Atmos Res 45:3-39

Milbrandt JA, McTaggart-Cowan M (2010) Sedimentation-induced errors in bulk microphysics schemes. J Atmos Sci 67:3931-3948

Milbrandt JA, Yau MK (2005a) A multimoment bulk microphysics parameterization. Part l: analysis of the role of the spectral shape parameter. J Atmos Sci 62:3051-3064

Milbrandt JA, Yau MK (2005b) A multimoment bulk microphysics parameterization. Part II: a proposed three-moment closure and scheme description. J Atmos Sci 62:3065-3081

Milbrandt JA, Yau MK (2006) A multimoment bulk microphysics parameterization. Part IV: sensitivity experiments. J Atmos Sci 63:3137-3159 
Mittal R, laccarino G (2003) Immersed boundary methods. Annu Rev Fluid Mech $37: 239-261$

Miura H (2007) An upwind-biased conservative advection scheme for spherical hexagonal-pentagonal grids. Mon Wea Rev 135:4038-4044

Miura H (2013) An upwind-biased conservative transport scheme for multi-stage temporal integrations on spherical icosahedral grids. Mon Wea Rev 141:4049-4068

Miura H, Skamarock WC (2013) An upwind-biased transport scheme using a quadratic reconstruction on spherical icosahedral grids. Mon Wea Rev 141:832-847

Miura H, Tomita H, Nasuno T, Iga S, Satoh M, Matsuno T (2005) A climate sensitivity test using a global cloud resolving model under an aqua planet condition. Geophys Res Lett 32:L19717, doi:1029/2005GL023672

Miura H, Satoh M, Tomita H, Nasuno T, Iga S, Noda AT (2007a) A short-duration global cloud-resolving simulation with a realistic land and sea distribution. Geophys Res Lett 34:L02804, doi:10.1029/2006GL027448

Miura H, Satoh M, Nasuno T, Noda AT, Oouchi K (2007b) A Madden-Julian Oscillation event realistically simulated by a global cloud-resolving model. Science 318:1763-1765

Miura H, Satoh M, Katsumata M (2009) Spontaneous onset of a Madden-Julian oscillation event in a cloud-system-resolving simulation. Geophys Res Lett 36:L13802, doi:10.1029/2009GL039056

Miyakawa T, Takayabu YN, Nasuno T, Miura H, Satoh M, Moncrieff MW (2012) Convective momentum transport by rainbands within a Madden-Julian oscillation in a global nonhydrostatic model with explicit deep convective processes. Part I: methodology and general results. J Atmos Sci 69:1317-1338

Miyakawa T, Satoh M, Miura H, Tomita H, Yashiro H, Noda AT, Yamada Y, Kodama C, Kimoto M, Yoneyama K (2014) Madden-Julian oscillation prediction skill of a new-generation global model demonstrated using a supercomputer. Nat Commun 5:3769, doi:10.1038/ncomms4769

Miyamoto Y, Kajikawa Y, Yoshida R, Yamaura T, Yashiro H, Tomita H (2013) Deep moist atmospheric convection in a sub-kilometer global simulation. Geophys Res Lett 40:4922-4926

Miyoshi T, Aranami K (2006) Applying a four-dimensional local ensemble transform Kalman filter (4D-LETKF) to the JMA Nonhydrostatic Model (NHM) SOLA 2:128-131

Miyoshi T, Kunii M (2011) The local ensemble transform Kalman filter with the weather research and forecasting model: experiments with real observations. Pure Appl Geophys 169:321-333

Miyoshi T, Yamane S (2007) Local ensemble transform Kalman filtering with an AGCM at a T159/L48 resolution. Mon Wea Rev 135:3841-3861

Mizuta R, Oouchi K, Yoshimura H, Noda A, Katayama K, Yukimoto S, Hosaka M, Kusunoki S, Kawai H, Nakagawa M (2005) 20-km-mesh global climate simulations using JMA-GSM model - mean climate states. J Meteor Soc Japan 84:165-185

Moeng CH, LeMone MA, Khairoutdinov M, Krueger SK, Bogenschutz PA, Randall DA (2009) The tropical marine boundary layer under a deep convection system: a large-eddy simulation study. J Model Earth Systems 1:16, doi:10.3894/JAMES.2009.1.16

Morrison H, Gettelman A (2008) A new two-moment bulk stratiform cloud microphysics scheme in the Community Atmospheric Model, version 3 (CAM3). Part I: description and numerical tests. J Climate 21:3642-3659

Morrison H, Curry JA, Khvorostyanov VI (2005) A new double-moment microphysics parameterization for application in cloud and climate models. Part I: description. J Atmos Sci 62:1665-1677

Muroi C, Toyoda E, Yoshimura H, Hosaka M, Sugi M (2002) Standard coding rule. Tenki 49:91-95 (in Japanese)

Nagashima T, Ohara T, Sudo K, Akimoto H (2010) The relative importance of various source regions on East Asian surface ozone. Atmos Chem Phys 10:11305-11322

Nakajima T, Tsukamoto M, Tsushima Y, Numaguti A, Kimura T (2000) Modeling of the radiative process in an atmospheric general circulation model. Appl Opt 39:4869-4878

Nakajima TY, Suzuki K, Stephens GL (2010) Droplet growth in warm water clouds observed by the A-Tran Part 1: sensitivity analysis of the MODIS-derived cloud droplet sizes. J Atmos Sci 67:1884-1896

Nakanishi M, Niino H (2006) An improved Mellor-Yamada level-3 model: its numerical stability and application to a regional prediction of advection fog. Boundary-Layer Meteor 119:397-407

Nakanishi M, Niino H (2009) Development of an improved turbulence closure model for the atmospheric boundary layer. J Meteor Soc Japan 87:895-912
Nakazawa T (1988) Tropical super clusters within intraseasonal variations over the western Pacific. J Meteor Soc Japan 66:823-839

Nasuno T (2008) Equatorial mean zonal wind in a global nonhydrostatic aquaplanet experiment. J Meteor Soc Japan 86A:219-236

Nasuno T (2013) Forecast skill of Madden-Julian Oscillation events in a global nonhydrostatic model during the CINDY2011/DYNAMO observation period. SOLA 9:69-73

Nasuno T, Satoh M (2011a) Properties of precipitation and in-cloud vertical motion in a global nonhydrostatic aquaplanet experiment. J Meteor Soc Japan 89:413-439

Nasuno T, Satoh M (2011b) Statistical relationship between maximum vertical velocity and surface precipitation of Tropical convective clouds in global nonhydrostatic aquaplanet experiment. J Meteor Soc Japan 89:553-561

Nasuno T, Tomita H, Iga S, Miura H, Satoh M (2007) Multi-scale organization of convection simulated with explicit cloud processes on an aqua planet. J Atmos Sci 64:1902-1921

Nasuno T, Tomita H, Iga S, Miura H, Satoh M (2008) Convectively coupled equatorial waves simulated by a global nonhydrostatic experiment on an aqua planet. J Atmos Sci 65:1246-1265

Nasuno T, Miura H, Satoh M, Noda AT, Oouchi K (2009) Multi-scale organization of convection in a global numerical simulation of the December 2006 MJO event using explicit moist processes. J Meteor Soc Japan 87:335-345

Neale RB, Hoskins BJ (2001) A standard test for AGCMs including their physical parameterizations: I: the proposal. Atmos Sci Lett 1:153-155, doi:10.1006/ asle.2000.0019

Ničkovic S, Gavrilov MB, Tosic IA (2002) Geostrophic adjustment on hexagonal grids. Mon Wea Rev 130:668-683

Niwa Y (2010) Numerical Study on Atmospheric Transport and Surface Source/ Sink of Carbon Dioxide, Dissertation. The University of Tokyo, Tokyo

Niwa Y, Tomita H, Satoh M, Imasu R (2011a) A three-dimensional icosahedral grid advection scheme preserving monotonicity and consistency with continuity for atmospheric tracer transport. J Meteorol Soc Jpn 89:255-268

Niwa Y, Patra PK, Sawa Y, Machida T, Matsueda H, Belikov D, Maki T, Ikegami M, Imasu R, Maksyutov S, Oda T, Satoh M, Takigawa M (2011b) Three-dimensional variations of atmospheric $\mathrm{CO}_{2}$ : aircraft measurements and multi-transport model simulations. Atmos Chem Phys 11:3359-13375

Niwa Y, Machida T, Sawa Y, Matsueda H, Schuck TJ, Brenninkmeijer CAM, Imasu $\mathrm{R}$, Satoh M (2012) Imposing strong constraints on tropical terrestrial $\mathrm{CO}_{2}$ fluxes using passenger aircraft based measurements. J Geophys Res 117:D11303, doi:10.1029/2012JD017474

Noda AT, Oouchi K, Satoh M, Tomita H, Iga S, Tsushima Y (2010) Importance of the subgrid-scale turbulent moist process: Cloud distribution in global cloud-resolving simulatioins. Atmos Res 96:208-217

Noda AT, Oouchi K, Satoh M, Tomita H (2012) Quantitative assessment of diurnal variation of tropical convection simulated by a global nonhydrostatic model without cumulus parameterization. J Climate 25:5119-5134

Ohfuchi W, Nakamura H, Yoshioka MK, Enomoto T, Takaya K, Peng X, Yamane S, Nishimura T, Kurihara Y, Ninomiya K (2004) 10-km mesh meso-scale resolving simulations of the global atmosphere on the Earth Simulator: Preliminary outcomes of AFES (AGCM for the Earth Simulator). J Earth Simulator 1:8-34

Ohno T, Satoh M (2014) On the warm core of the tropical cyclone formed near the tropopause. J Atmos Sci in press

Onogi K, Tsutsui H, Koide H, Sakamoto M, Kobayashi S, Hatsushika H, Matsumoto T, Yamazaki N, Kamahori H, Takahashi K, Kadokura S, Wada K, Kato K, Oyama R, Ose T, Mannoji N, Taira T (2007) The JRA-25 reanalysis. J Meteorol Soc Jpn 85:369-432

Oouchi K, Noda AT, Satoh M, Miura H, Tomita H, Nasuno T, Iga S (2009a) A simulated preconditioning of typhoon genesis controlled by a boreal summer Madden-Julian Oscillation event in a global cloud-system-resolving model. SOLA 5:65-68

Oouchi K, Noda AT, Satoh M, Wang B, Xie S-P, Takahashi HG, Yasunari T (2009b) Asian summer monsoon simulated by a global cloud-system-resolving model: Diurnal to intra-seasonal variability. Geophys Res Lett 36:L11815, doi:10.1029/2009GL038271

Oouchi K, Taniguchi H, Nasuno T, Satoh M, Tomita H, Yamada Y, Ikeda M, Shirooka R, Yamada H, Yoneyama K (2012) A Prototype Quasi Real-Time Intra-Seasonal Forecasting of Tropical Convection Over the Warm Pool Region: A new Challenge of Global Cloud-System-Resolving Model for a Field Campaign. In: Oouchi K, Fudeyasu H (eds) Cyclones: Formation, Triggers and Control. Nova Science Publishers Inc, pp 233-248 
Oouchi K, Satoh M, Yamada Y, Tomita H, Sugi M (2014) A hypothesis and a casestudy projection of an influence of MJO modulation on boreal-summer tropical cyclogenesis in a warmer climate with a global non-hydrostatic model: a transition toward the central Pacific? Front Earth Sci 2:1, doi:10.3389/feart.2014.00001 (accepted)

Ott E, Hunt BR, Szunyogh I, Zimin AV, Kostelich EJ, Corazza M, Kalnay E, Patil DJ, Yorke JA (2004) A local ensemble Kalman filter for atmospheric data assimilation. Tellus 56A:415-428

Patra PK, Law RM, Peters W, Rödenbeck C, Takigawa M, Aulagnier C, Baker I, Bergmann DJ, Bousquet P, Brandt J, Bruhwiler L, Cameron-Smith PJ, Christensen $J$ H, Delage F, Denning AS, Fan S, Geels C, Houweling S, Imasu R, Karstens U, Kawa SR, Kleist J, Krol MC, Lin SJ, Lokupitiya R, Maki T, Maksyutov S, Niwa Y, Onishi R, Parazoo N et al (2008) TransCom model simulations of hourly atmospheric $\mathrm{CO}_{2}$ : analysis of synoptic scale variations for the period 2002-2003. Global Biogeochem Cycles 22:GB4013, doi:10.1029/2007GB003081

Patra PK, Canadell JG, Houghton RA, Piao SL, Oh N-H, Ciais P, Manjunath KR, Chhabra A, Wang T, Bhattacharya T, Bousquet P, Hartman J, Ito A, Mayorga E, Niwa Y, Raymond P, Sarma WSS, Lasco R (2013) The carbon budget of South Asia. Biogeoscience 10:513-527

Phillips VTJ, Donner LJ, Garner ST (2007) Nucleation processes in deep convection simulated by a cloud-system-resolving model with doublemoment bulk cloud microphysics. J Atmos Sci 64:738-761

Pruppacher HR, Klett JD (1997) Microphysics of Clouds and Precipitation. Kluwer Academic Publisher, Heidelberg, p 954

Putman WM, Suarez M (2011) Cloud-system resolving simulations with the NASA Goddard Earth Observing System global atmospheric model (GEOS-5). Geophys Res Lett 38:L16809, doi:10.1029/2011GL048438

Qian J-H, Semazzi FHM, Scroggs JS (1998) A global nonhydrostatic semi-Lagrangian atmospheric model with orography. Mon Wea Rev 126:747-771

Randall DA (1994) Geostrophic adjustment and the finite-difference shallowwater equations. Mon Wea Rev 122:1371-1377

Randall DA, Heikes R, Ringler T (2000) Global Atmospheric Modeling Using a Geodesic Grid With an Isentropic Vertical Coordinate. In: General Circulation Model Development, Chapter 17. Academic Press, California London, pp 509-538

Randall DA, Khairoutdinov M, Arakawa A, Grabowski WW (2003) Breaking the cloud-parameterization deadlock. Bull Amer Meteor Soc 84:1547-1564

Redler R, Valcke S, Ritzdorf H (2009) OASIS-4 - a coupling software for next generation earth system modeling. Geoscientific Model Development Discussions 2:797-843

Ringler TD, Randall DA (2002) A potential enstrophy and energy conserving numerical scheme for solution of the shallow-water equations on a geodesic grid. Mon Wea Rev 130:1397-1410

Ringler TD, Heikes RH, Randall DA (2000) Modeling the atmospheric general circulation using a spherical geodesic grid: a new class of dynamical cores. Mon Wea Rev 128:2471-2490

Roh W, Satoh M (2014) Evaluation of precipitating hydrometeor parameterizations in a single-moment bulk microphysics scheme for deep convective systems over the tropical open ocean. J Atmos Sci 71:2654-2673

Rossow WB, Schiffe RA (1999) Advances in understanding clouds from ISCCP. Bull Am Meteorol Soc 80:2261-2287

Rotunno R, Emanuel KA (1987) An air-sea interaction theory for tropical cyclones. Part II: evolutionary study using a nonhydrostatic axisymmetric numerical model. J Atmos Sci 44:542-561

Rutledge SA, Hobbs P (1983) The mesoscale and microscale structure and organization of clouds and precipitation in midlatitude cyclones. VIII: a model for the "seeder-feeder" process in warm-frontal rainbands. J Atmos Sci 40:1185-1206

SALSA (2014) Annual report of Development of Seamless Chemical AssimiLation System and its Application for Atmospheric Environmental Materials (SALSA). In: Project of the Research Program on Climate Change Adaptation (RECCA) in Ministry of Education and Sports in Japan (MEXT). Aavailable at http:// 157.82.240.167/ salsa/Program/SALSA_Annual_Report_FY2013.pdf. Accessed at 29 Sep 2014

Sato T, Miura H, Satoh M (2007) Spring diurnal cycle of clouds over Tibetan Plateau: global cloud-resolving simulations and satellite observations. Geophys Res Lett 34:L18816, doi:10.1029/2007GL030782

Sato T, Yoshikane T, Satoh M, Miura H, Fujinami H (2008) Resolution dependency of the diurnal cycle of convective clouds over the Tibetan Plateau in a mesoscale model. J Meteor Soc Japan 86A:17-31

Sato T, Miura H, Satoh M, Takayabu YN, Wang Y (2009) Diurnal cycle of precipitation in the tropics simulated in a global cloud-resolving model. J Climate 22:4809-4826
Satoh M (2002) Conservative scheme for the compressible non-hydrostatic models with the horizontally explicit and vertically implicit time integration scheme. Mon Wea Rev 130:1227-1245

Satoh M (2003) Conservative scheme for a compressible nonhydrostatic model with moist processes. Mon Wea Rev 131:1033-1050

Satoh M (2013) Atmospheric Circulation Dynamics and General Circulation Models, 2nd edn. Springer-PRAXIS, Heidelberg, p 730

Satoh M, Kitao Y (2013) Numerical examination of the diurnal variation of summer precipitation over southern China. SOLA 9:129-133

Satoh M, Matsuda Y (2009) Statistics of high-cloud areas and its sensitivity to cloud microphysics with single cloud experiments. J Atmos Sci 66:2659-2677

Satoh M, Tomita H, Miura H, Iga S, Nasuno T (2005) Development of a global cloud resolving model - a multi-scale structure of tropical convections. J Earth Simulator 3:11-19

Satoh M, Matsuno T, Tomita H, Miura H, Nasuno T, Iga S (2008) Nonhydrostatic icosahedral atmospheric model (NICAM) for global cloud resolving simulations. J Comput Phys 227:3486-3514

Satoh M, Inoue T, Miura H (2010) Evaluations of cloud properties of global and local cloud system resolving models using CALIPSO and CloudSat simulators. J Geophys Res 115:D00H14, doi:10.1029/2009JD012247

Satoh M, Oouchi K, Nasuno T, Taniguchi H, Yamada Y, Tomita H, Kodama C, Kinter J III, Achuthavarier D, Manganello J, Cash B, Jung T, Palmer T, Wedi N (2012a) The Intra-Seasonal Oscillation and its control of tropical cyclones simulated by high-resolution global atmospheric models. Clim Dyn 39:2185-2206

Satoh M, Iga S, Tomita H, Tsushima Y, Noda AT (2012b) Response of upper clouds due to global warming tested by a global atmospheric model with explicit cloud processes. J Climate 25:2178-2191

Satoh M, Nihonmatsu R, Kubokawa H (2013) Environmental conditions for tropical cyclogenesis associated with African easterly waves. SOLA 9:120-124

Sawa Y, Machida T, Matsueda H (2012) Aircraft observation of the seasonal variation in the transport of $\mathrm{CO}_{2}$ in the upper atmosphere. J Geophys Res 117:D05305, doi:10.1029/2011JD016933

Seifert A (2008) On the parameterization of evaporation of raindrops as simulated by a one-dimensional rainshaft model. J Atmos Sci 65:3608-3619

Seifert A, Beheng KD (2001) A double-moment parameterization for simulating autoconversion, accretion and selfcollection. Atmos Res 59-60:265-281

Seifert A, Beheng KD (2006) A two-moment cloud microphysics parameterization for mixed-phase clouds. Part I: model description. Meteorol Atmos Phys 92:45-66

Seifert A, Khain A, Pokrovsky A, Beheng KD (2006) A comparison of spectral bin and two-moment bulk mixed-phase cloud microphysics. Atmos Res 80:46-66

Seiki T, Nakajima T (2014) Aerosol effects of the condensation process on a convective cloud simulation. J Atmos Sci 71:833-853

Seiki T, Satoh M, Tomita H, Nakajima T (2014) Simultaneous evaluation of ice cloud microphysics and non-sphericity of the cloud optical properties using hydrometeor video sonde and radiometer sonde in-situ observations. J Geophys Res 119:6681-6701, doi:10.1002/2013JD021086

Sekiguchi M, Nakaima T (2008) A k-distribution-based radiation code and its computational optimization for an atmospheric general circulation model. J Quant Spectrosc Radiat Transfer 109:2779-2793

Semazzi FHM, Qian J-H, Scroggs JS (1995) A global nonhydrostatic semi-Lagrangian atmospheric model without orography. Mon Wea Rev 123:2534-2550

Sherwood SC, Ingram W, Tsushima Y, Satoh M, Roberts M (2010) Relative humidity changes in a warmer climate. J Geophys Res 115:D09104, doi:10.1029/2009JD012585

Shindell DT, Miller RL, Schmidt GA, Pandolfo L (1999) Simulation of recent northern winter climate trends by greenhouse-gas forcing. Nature 399:452-455

Shipway BJ, Hill AA (2012) Diagnosis of systematic differences between multiple parametrizations of warm rain microphysics using a kinematic framework. Quart J Roy Meteor Soc 138:2196-2211

Simmons AJ, Burridge DM (1981) An energy and angular-momentum conserving vertical finite-difference scheme and hybrid vertical-coordinates. Mon Wea Rev 109:758-766

Skamarock WC, Klemp JB, Duda MG, Fowler LD, Park S-H (2012) A multi-scale nonhydrostatic atmospheric model using centroid Vornoi tesselations and C-grid staggering. Mon Wea Rev 140:3090-3105

Sohn BJ, Nakajima T, Satoh M, Jang H-S (2010) Impact of different definitions of clear-sky flux on the determination of longwave cloud radiative forcing: NICAM simulation results. Atmos Chem Phys 10:11641-11646 
Staniforth A, Wood N (2008) Aspects of the dynamical core of a nonhydrostatic, deep-atmosphere, unified weather and climate-prediction model. J Comput Phys 227:3445-3464

Steppeler J, Bitzer HW, Minotte M, Bonaventura L (2002) Nonhydrostatic atmospheric modeling using a z-coordinate representation. Mon Wea Rev 130:2143-2149

Steppeler J, Bitzer HW, Janjic Z, Schättler U, Prohl P, Gjertsen U, Torrisi L, Parfinievicz J, Avgoustoglou E, Damrath U (2006) Prediction of clouds and rain using a z-coordinate nonhydrostatic model. Mon Wea Rev 134:3625-3643

Stuhne GR, Peltier WR (1996) Vortex erosion and amalgamation in a new model of large scale flow on the sphere. J Comput Phys 128:58-81

Sudo K, Akimoto H (2007) Global source attribution of tropospheric ozone: long-range transport from various source regions. J Geophys Res 112:D12302, doi:10.1029/2006JD007992

Sudo K, Takahashi M, Kurokawa J, Akimoto H (2002a) CHASER: A global chemical model of the troposphere: 1. Model description. J Geophy Res 107:4339, doi:10.1029/2001JD001113

Sudo K, Takahashi M, Akimoto H (2002b) CHASER: a global chemical model of the troposphere 2. Model results and evaluation. J Geophys Res 107:4586

Suzuki K, Nakajima T, Satoh M, Tomita H, Takemura T, Nakajima TY, Stephens GL (2008) Global cloud-system-resolving simulation of aerosol effect on warm clouds. Geophys Res Lett 35:L19817, doi:10.1029/2008GL035449

Takata K, Emori S, Watanabe T (2003) Development of the minimal advanced treatments of surface interaction and runoff. Global and Planetary Change 38:209-222

Takayabu YN, Iguchi T, Kachi M, Shibata A, Kanzawa H (1999) Abrupt termination of the 1997-98 El Nino in response to a Madden-Julian oscillation. Nature 402:279-282

Takemura T, Okamoto H, Maruyama Y, Numaguti A, Higurashi A, Nakajima T (2000) Global three-dimensional simulation of aerosol optical thickness distribution of various origins. J Geophys Res 105:17853-17873

Takemura T, Nakajima T, Dubovik O, Holben BN, Kinne S (2002) Single scattering albedo and radiative forcing of various aerosol species with a global three-dimensional model. J Climate 15:333-352

Takemura T, Nozawa T, Emori S, Nakajima TY, Nakajima T (2005) Simulation of climate response to aerosol direct and indirect effects with aerosol transportradiation model. J Geophys Res 110:D02202, doi:10.1029/2004JD005029

Takemura T, Egashira M, Matsuzawa L, Ichijo H, O'ishi R, Abe-Ouchi A (2009) A simulation of the global distribution and radiative forcing of soil dust aerosols at the Last Glacial Maximum. Atmos Chem Phys 9:3061-3073

Taniguchi H, Yanase W, Satoh M (2010) Ensemble simulation of cyclone Nargis by a global cloud-system-resolving model-modulation of cyclogenesis by the Madden-Julian Oscillation. J Meteor Soc Japan 88:571-591

Tans PP, Fung IY, Takahashi T (1990) Observational constrains on the global atmospheric $\mathrm{CO}_{2}$ budget. Science 274:1431-1438

Tarantola A (2005) Inverse problem theory and methods for model parameter estimation. Soc Ind Appl Math, Philadelphia, p 342, doi:10.1137/ 1.9780898717921

Taylor M, Tribbia J, Iskandarani M (1997) The spectral element method for the shallow water equations on the sphere. J Comp Phys 130:92-108

Terasaki K, Tanaka HL, Satoh M (2009) Characteristics of the kinetic energy spectrum of NICAM. SOLA 5:180-183

Thompson G, Field PR, Rasmussen RM, Hall WD (2008) Explicit forecasts of winter precipitation using an improved bulk microphysics scheme. Part II: implementation of a new snow parameterization. Mon Wea Rev 136:5095-5115

Thuburn J, Ringler T, Skamarock WC, Klemp JB (2009) Numerical representation of geostrophic modes on arbitrarily structured C-grids. J Comput Phys 228:8321-8335

Tomita H (2008a) A stretched icosahedral grid by a new grid transformation. J Meteor Soc Japan 86A:107-119

Tomita H (2008b) New microphysical schemes with five and six categories by diagnostic generation of cloud ice. J Meteor Soc Japan 86:121-142

Tomita H, Satoh M (2004) A new dynamical framework of nonhydrostatic global model using the icosahedral grid. Fluid Dyn Res 34:357-400

Tomita H, Tsugawa M, Satoh M, Goto K (2001) Shallow water model on a modified icosahedral geodesic grid by using spring dynamics. J Comp Phys 174:579-613

Tomita H, Satoh M, Goto K (2002) An optimization of icosahedral grid modified by spring dynamics. J Comp Phys 183:307-331
Tomita H, Miura H, Iga S, Nasuno T, Satoh M (2005) A global cloud-resolving simulation: preliminary results from an aqua planet experiment. Geophys Res Lett 32:L08805, doi:10.1029/2005GL022459

Tomita H, Goto K, Satoh M (2008) A new approach of atmospheric general circulation model: Global cloud resolving model NICAM and its computational performance. SIAM J Sci Comp 30:2755-2776

Trenberth K, Fasullo FT, Kiehl J (2009) Earth's global energy budget. Bull Amer Meteor Soc 90:311-323

Tsuchiya C, Sato K, Nasuno T, Noda AT, Satoh M (2011) Universal frequency spectra of surface meteorological fluctuations. J Climate 24:4718-4732

Tsushima Y, Iga S, Tomita H, Satoh M, Noda AT, Webb M (2014) High cloud increase in a perturbed SST experiment with a global nonhydrostatic model including explicit convective processes. J Adv Model Earth Syst 06:, doi:10.1002/2013MS000301

Wacker U, Seifert A (2001) Evolution of rain water profiles resulting from pure sedimentation: spectral vs. parameterized description. Atmos Res 58:19-39

Walko RL, Cotton WR, Meyers MP, Harrington JY (1995) New RAMS cloud microphysics parameterization. Part l: the single-moment scheme. Atmos Res 38:29-62

Watanabe M, Emori S, Satoh M, Miura H (2009) A PDF-based hybrid prognostic cloud scheme for general circulation models. Clim Dyn 33:795-816

Watanabe M, Suzuki T, O'ishi R, Komuro Y, Watanabe S, Emori S, Takemura T, Chikira M, Ogura T, Sekiguchi M, Takata K, Yamazaki D, Yokohata T, Nozawa T, Hasumi H, Tatebe H, Kimoto M (2010) Improved climate simulation by MIROC 5: mean states, variability, and climate sensitivity. J Climate 23:6312-6335

Watanabe S, Hajima T, Sudo K, Nagashima T, Takemura T, Okajima H, Nozawa T, Kawase $\mathrm{H}$, Abe M, Yokohata T, Ise T, Sato H, Kato E, Takata K, Emori S, Kawamiya M (2011) MIROC-ESM 2010: model description and basic results of CMIP5-20c3m experiments. Geosci Model Dev 4:845-872

Webb M, Senior C, Bony S, Morcrette JJ (2001) Combining ERBE and ISCCP data to assess clouds in the Hadley Centre, ECMWF and LMD atmospheric climate models. Clim Dyn 17:905-922

Wedi NP (2014) Increasing horizontal resolution in numerical weather prediction and climate simulations: illusion or panacea? Philos Trans R A 372:20130289

Wedi NP, Smolarkiewicz PK (2009) A framework for testing global non-hydrostatic models. Q J R Meteorol Soc 135:469-484

Wielicki BA, Barkstrom BR, Harrison EF, Lee RB, Smith GL, Cooper JE (1996) Clouds and the Earth's Radiant Energy System (CERES): an earth observing system experiment. Bull Amer Meteor Soc 77:853-868

Williamson DL, Drake JB, Hack JJ, Jakob R, Swarztrauber PN (1992) A standard test set for numerical approximations to the shallow water equations in spherical geometry. J Comp Phys 102:211-224

Wood N, Staniforth A, White A, Allen T, Diamantakis M, Gross M, Melvin T, Smith C, Vosper S, Zerroukat M, Thuburn J (2013) An inherently mass-conserving semi-implicit semi-Lagrangian discretization of the deep-atmosphere global non-hydrostatic equations. Q J R Meteorol Soc 140:1505-1520, doi:10.1002/ qj.2235

Wyngaard JC (2004) Toward numerical modeling in the "Terra Incognita". J Atmos Sci 61:1816-1826

Xiao F, Okazaki T, Satoh M (2003) An accurate semi-Lagrangian scheme for rain drop sedimentation. Mon Wea Rev 131:974-983

Yamada Y, Satoh M (2013) Response of ice and liquid water paths of tropical cyclones to global warming simulated by a global nonhydrostatic model with explicit cloud microphysics. J Climate 26:9931-9945

Yamada Y, Oouchi K, Satoh M, Tomita H, Yanase W (2010) Projection of changes in tropical cyclone activity and cloud height due to greenhouse warming: global cloud-system-resolving approach. Geophys Res Lett 37:L07709, doi:10.1029/2010GL042518

Yamada Y, Oouchi K, Satoh M, Noda AT, Tomita H (2012) Sensitivity of Tropical Cyclones to Large-Scale Environment in a Global non-Hydrostatic Model With Explicit Cloud Microphysics. In: Oouchi K, Fudeyasu H (eds) Cyclones: formation, Triggers and Control. Nova Science, pp 145-159

Yamaura T, Kajikawa Y, Tomita H, Satoh M (2013) Possible impact of a tropical cyclone on the northward migration of the Baiu frontal zone. SOLA 9:89-93

Yamazaki H, Satomura T (2008) Vertically combined shaved cell method in z-coordinate for non-hydrostatic atmospheric model. Atmos Sci Lett 9:171-175

Yamazaki H, Satomura T (2010) Nonhydrostatic atmospheric modeling using a combined cartesian grid. Mon Wea Rev 138:3932-3945

Yanase W, Taniguchi H, Satoh M (2010a) Environmental modulation and numerical predictability associated with the genesis of tropical cyclone Nargis (2008). J Meteor Soc Japan 88:497-519 
Yanase W, Satoh M, Yamada H, Yasunaga K, Moteki Q (2010b) Continual influences of tropical waves on the genesis and rapid intensification of typhoon Durian (2006). Geophys Res Lett 37:L08809, doi:10.1029/2010GL042516

Yanase W, Satoh M, Taniguchi H, Fujinami H (2012a) Seasonal and intraseasonal modulation of tropical cyclogenesis environment over the Bay of Bengal during the extended summer monsoon. J Clim 25:2914-2930

Yanase W, Satoh M, Iga S, Chan JCL, Fudeyasu H, Wang Y, Oouchi K (2012b) Multi-Scale Dynamics of Tropical Cyclone Formations in an Equilibrium Simulation Using a Global Cloud-System Resolving Model. In: Oouchi K, Fudeyasu H (eds) Cyclones: formation, triggers and control. Nova Science, pp 221-231

Yasunaga K, Nasuno T, Miura H, Takayabu YN, Yoshizaki M (2013) Afternoon precipitation peak simulated in an aqua-planet global non-hydrostatic model (aqua-planet-NICAM). J Meteor Soc Japan 91A:217-229

Yeh K-S, Côté J, Gravel S, Méthot A, Patoine A, Roch M, Staniforth A (2002) The CMC-MRB global environmental multiscale (GEM) model. Part III: nonhydrostatic formulation. Mon Wea Rev 120:329-356

Yoneyama K, Katsumata M, Mizuno K, Yoshizaki M, Shirooka R, Yasunaga K, Yamada H, Sato N, Ushiyama T, Moteki Q, Seiki A, Fujita M, Ando K, Hase H, Ueki I, Horii T, Masumoto Y, Kuroda Y, Takayabu YN, Shareef A, Fujiyoshi Y, McPhaden MJ, Murty VSN, Yokoyama C, Miyakawa T (2008) MISMO field experiment in the equatorial Indian Ocean. Bull Am Meteorol Soc 89:1889-1903

Yoneyama K, Zhang C, Long CN (2013) Tracking pulses of the Madden-Julian Oscillation. Bull Amer Meteor Soc 94:1871-1891

Yoshimura H, Yukimoto S (2008) Development of a simple coupler (Scup) for earth system modeling. Pap Met Geophys 59:19-29

Yoshizaki M, Iga S, Satoh M (2012a) Eastward propagating property of large-scale precipitation systems simulated in the coarse-resolution NICAM and an explanation of its formation. SOLA 8:21-24

Yoshizaki M, Yasunaga K, Iga S, Satoh M, Nasuno T, Noda AT, Tomita H (2012b) Why do super clusters and Madden Julian Oscillation exist over the equatorial region? SOLA 8:33-36

Zängl G, Tomita H, Satoh M, Ludwig T, Linardakis L, Thuburn J, Dubos T (2011) ICOMEX: ICOsahedral-grid Models for EXascale Earth system simulations. IS-ENES Workshop, Lecce

Zängl G, Reinert D, Rípodas P, Baldauf M (2014) The ICON (ICOsahedral Non-hydrostatic) modelling framework of DWD and MPI-M: Description of the non-hydrostatic dynamical core. Quart J Roy Meteor Soc, doi:10.1002/qj.2378

doi:10.1186/s40645-014-0018-1

Cite this article as: Satoh et al:: The Non-hydrostatic Icosahedral

Atmospheric Model: description and development. Progress in Earth and Planetary Science 2014 1:18.

\section{Submit your manuscript to a SpringerOpen ${ }^{\circ}$ journal and benefit from:}

- Convenient online submission

- Rigorous peer review

- Immediate publication on acceptance

- Open access: articles freely available online

- High visibility within the field

- Retaining the copyright to your article

Submit your next manuscript at $\gg$ springeropen.com 